\title{
Evolution Mechanism of Meandering River Downstream Gigantic Hydraulic Project I: Hydrodynamic Models and Verification
}

\author{
Linshuang Liu, ${ }^{1}$ Haiqing Zhu $\mathbb{D}^{2},{ }^{2}$ Chengtao Huang, ${ }^{1}$ and Li Zheng ${ }^{1}$ \\ ${ }^{1}$ Changjiang Waterway Institute of Planning, Design \& Research, Wuhan, Hubei Province 430040, China \\ ${ }^{2}$ School of Civil Engineering and Architecture, Wuhan Institute of Technology, Wuhan, Hubei Province 430073, China
}

Correspondence should be addressed to Haiqing Zhu; zhq7751@163.com

Received 30 April 2018; Accepted 19 August 2018; Published 12 November 2018

Academic Editor: Cornelio Posadas-Castillo

Copyright (C) 2018 Linshuang Liu et al. This is an open access article distributed under the Creative Commons Attribution License, which permits unrestricted use, distribution, and reproduction in any medium, provided the original work is properly cited.

\begin{abstract}
The evolution mechanism of meandering river is one of essential references to predict the evolution disciplines of meandering river. Jingjiang curved reaches are the typical meandering river; more specifically, they are located downstream the gigantic hydraulic project named Three Gorge Project (TGP). Because the incoming water and sediment condition have been changed by the gigantic project, the evolution behavior of Jingjiang curved reaches changes a lot, making the evolution behavior unpredictable. However, traditional two-dimensional (2D) hydrodynamic model could not simulate the transportation characteristics of unbalanced and suspended sediment, leading the predict results of 2D model are far from the measured data. This paper presents a theoretical and numerical approach that explores the evolution mechanism of meandering river downstream gigantic hydraulic project. Firstly, the evolution behavior and evolution disciplines of Jingjiang curved reaches were classified before and after the hydraulic project implement respectively. Secondly, a 2D hydrodynamic model was set up and verified according to the measured data. And then a superior three-dimensional (3D) numerical model, whose boundary conditions were simulated by the results of the 2D numerical model, considering the unbalanced water and sediment transportation properties, was developed and verified by the measured data. Research results show that the 2D model displayed a reasonable accuracy in predicting the water level, branch diversion ratio, and flow velocity; the 3D model displayed a better accuracy in predicting the water lever, vertical flow velocity, longitudinal flow velocity, sediment concentration, and sediment variable quantity. Both 2D and 3D models could be applied to study the evolution mechanism of meandering river; especially the proposed 3D model considering the sediment transport in longitudinal, transverse, and vertical directions will improve the accuracy of behavior prediction and will help decision-making for the river regulation.
\end{abstract}

\section{Introduction}

TGP is the largest water conservation project in human history. It started on December 14, 1994; test impoundment began on June 1, 2003, and impounded to the normal water level (means above the sea level $175 \mathrm{~m}$ ) on October 26, 2010. It provides comprehensive benefits including flood control, hydropower, shipping, and water supply [1]. At the meanwhile, the great project changes the intrinsic circumstance of water and sediment, which has a substantial influence on the evolution laws of the downstream reaches, especially reaches near TGP [2].

Jingjiang reach, in middle Yangtze River, is a typical meandering river, and it is the nearest meandering reach downstream the TGP. Jingjiang reach consists of 16 local curved reaches, shown as Figure 1, (1) Guanzhou curved reach (CR), (2) Jiangkou CR, (3) Yuanshi CR, (4) Shashi CR, (5) Maijiazhai CR, (5) Haoxue CR, (7) Ouchikou CR, (8) Nianziwan CR, (9) Tiaoguan CR, (10) Laijiapu CR, (11) Jianli CR, (12) Zhuanqiao CR, (13) Fanzui CR, (14) Xiongjiazhou CR, (15) Qigongling CR, and (16) Guanyingzhou CR.

Under the natural condition, curved reach follows the traditional evolution disciplines including the following: (1) in the low water period, the main stream will go along the river bank; (2) in the high water period, the main stream will go downstream directly; (3) in the long term, concave bank will be scoured while convex bank will be deposited 


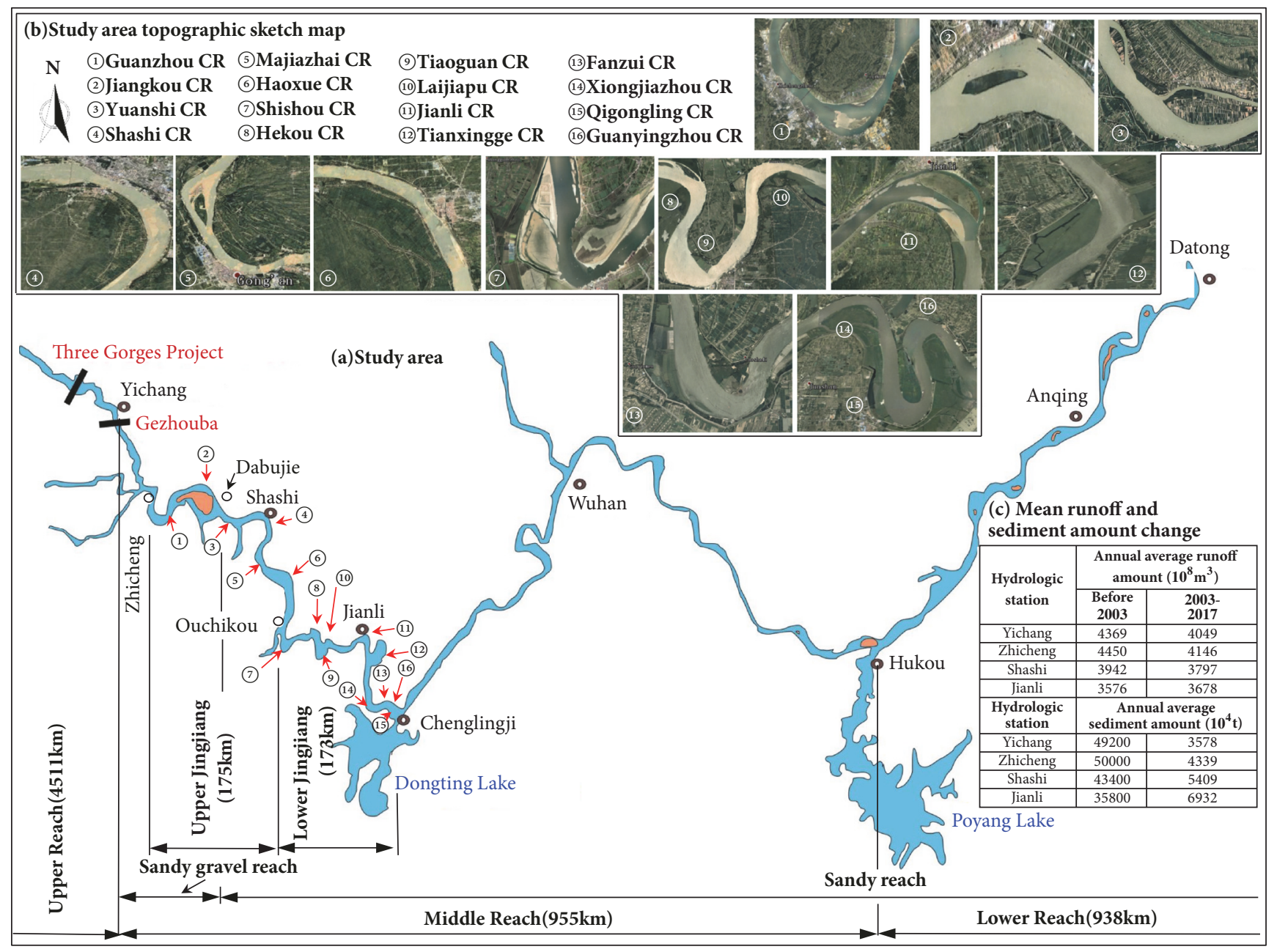

FIGURE 1: Schematic of the covered reach in the downstream of the TGD.

[3-7] (Schumm, 1960). Jingjiang reach followed the above disciplines until the TGD was established.

Present researches [8-10] and measured data (shown in Figure 2) showed that, after Three Gorge Reservoir impoundment, water and sediment go downstream changed and brought about new evolution disciplines such like: (1) in the flood period, flood peak decreased; (2) in the dry period, total water 65 flow increased; (3) the duration of normal water period increased; (4) sediment went to the downstream driver decreased dramatically, usually decreased more than $80 \%$. In recent years, we have observed that in Jingjiang reach, some concave banks begin to deposit while some convex banks begin to scour which present an opposite disciplines to the traditional disciplines. For example, in (5) Maijiazhai CR and (8) Nianziwan CR, the convex bank beach has been scoured while the concave bank bed has been deposited obviously. The concave bank beds of (9) Tiaoguan CR and (13) Fanzui CR have been deposited severely, forming a new diara near the concave bank. Conversely, there ought to be a deposit at the convex of (15) Qigongling CR, but it has been scoured severely, and the convex bank bed has been cut into two parts by a small ditch at the end of the convex band bed. Therefore, river beach and groove distribution tend to be unpredictable and would impact the flood control, irrigation, and shipping of the downstream of Yangtze River.

In brief, water and sediment transport of curved reach in longitudinal, transverse, and vertical directions are strong. However, the traditional two-dimensional (2D) numerical model could not work very well on the complicated dynamic circumstance.

This paper presents a theoretical and numerical study on the evolution disciplines of the downstream Yangtze River. Firstly, the evolution properties were summarized and classified according to history measured data. Then a two-dimensional (3D) numerical model was set up and verified according to the measured data. At last a superior three-dimensional (3D) numerical model, whose boundary conditions were simulated by the results of the $2 \mathrm{D}$ numerical model, considering the unbalanced water and sediment transportation properties, was developed and verified by the measured data. Results show that the proposed 3D model displayed a reasonable agreement on measured data and could be used to study the evolution mechanism of meandering river. 

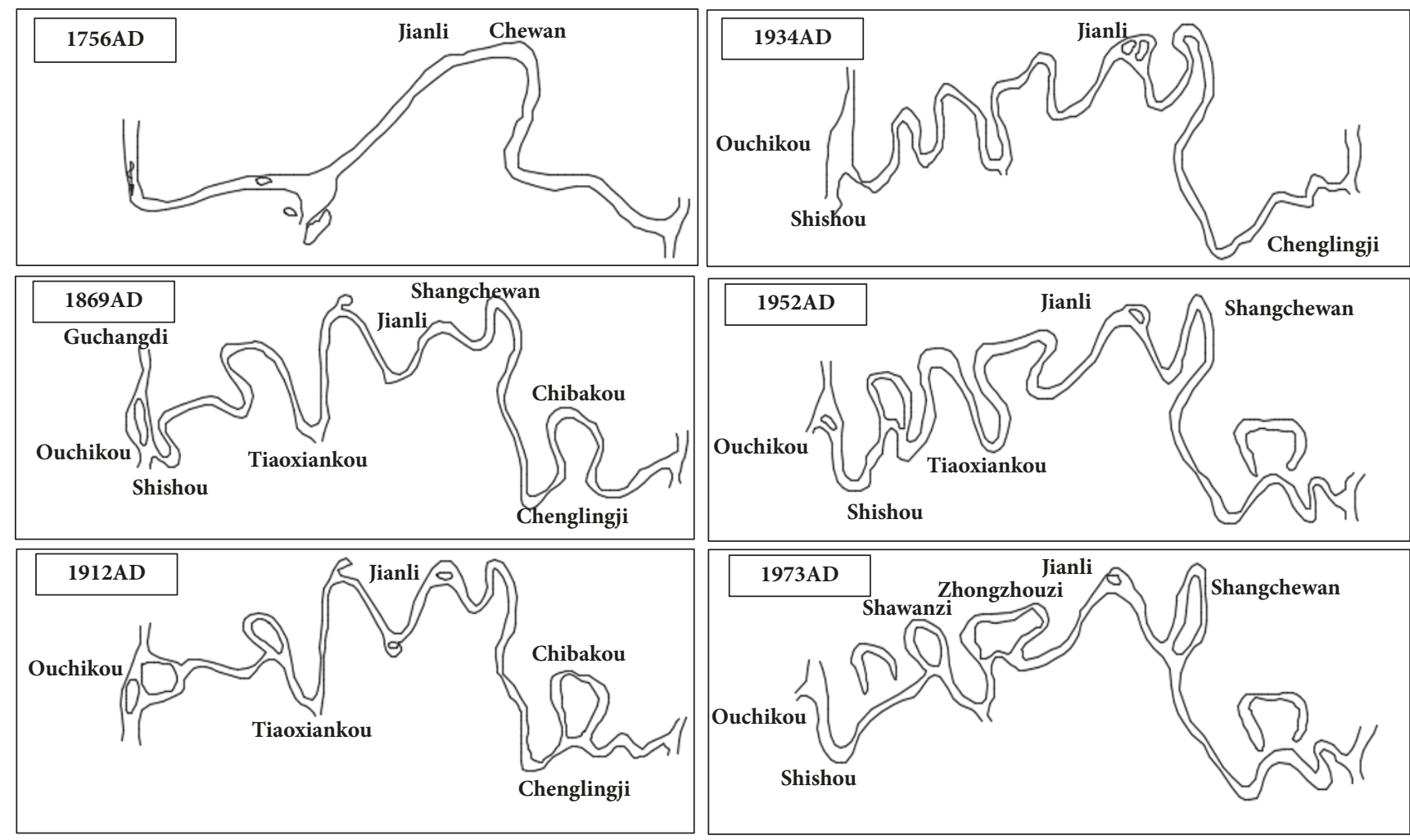

FIGURE 2: Evolution history of Jingjiang reach downstream of the TGD.

\section{Evolution Properties of Meandering River}

2.1. Before the TGD Impounded Water. Jingjing reach originated from Yunmeng settlement in the Tertiary period, and then the channel changed frequently under the natural circumstance with complicated mechanism. As recorded literature [11-13], it experienced four periods: (1) formation of the delta bed; (2) attenuation of the delta bed; (3) formation of the meandering reach; and (4) propagation of the meandering reach.

Jingjiang reach can be divided into two parts at Ouchikou: (1) upper-Jingjiang reach, between Zhicheng and Ouchikou, and (2) lower-Jingjiang reach, between Ouchikou to Chenglingji [14]. In the last three hundred years, upperJingjiang reach evolved lightly while lower-Jingjiang reach evolved severely, shown as Figure 2. It shows that upperJingjiang reach wiggled its river bed gradually, but the river channel kept its general configuration. Lower-Jingjiang reach wiggled its river bed frequently, forming and attenuating meanders, making the river alternately go downstream curvedly and directly. In order to control the original propagation, a series of drainage valves, levee construction, and bank protection projects had been set up along Jingjiang reach. Till 1970s, the artificial facilities have made great difference for slowing down the wigging of the river bed $[11,15]$. For example, because of man-made cut-bend projects at Zhongzhouzi and Shangchewan (shown in Figure 2, in the picture $1973 \mathrm{AD}$ ), along with the effect of natural cutbend at Shatanzi, wigging of lower-Jingjiang reach has been controlled generally.
Before impounding of TGR (from 1970s to year 2003), in the low water period, the main stream in curved reaches went along the channel bank; in the high water period, the main stream went downstream directly $[11,14,16]$. It followed the traditional evolution disciplines: concave bank scoured while convex bank deposited, shown as Figures 3(a) and 3(b). In general, the evolution disciplines of Jingjiang reach presented two types:

(1) Type A, concave bank was scoured while convex bank was deposited. For most curving reaches, concave bank was scoured while convex bank was deposited; as a result meandering radius of the river will decline gradually, such as (4) Shishou CR, (9) Tiaoguan CR, (10) Laijiapu CR, (11) Jianli CR, and 13 Fanzui CR.

(2) Type B, convex bank was scoured and will even be cut-bend. For minority meandering reaches, under the effects of natural incoming water and river bank boundaries, the convex was scoured and even a little groove could propagate to be a natural cut-bend channel, making the meandering reach into straight reach, such as (14) Xiongjiazhou CR, (15) Qigongling CR, and (16) Guanyingzhou CR.

2.2. After the TGD Impounded Water. The incoming water and sediment changed dramatically after impoundment of TGR [15, 17-19]; consequently the evolution disciplines of the downstream curved reach changed as follows.

(1) Type A has changed into an opposite appearance, which means concave bank was deposited while convex bank scoured, such as Shashi CR, Hekou CR, Laijiapu CR, 


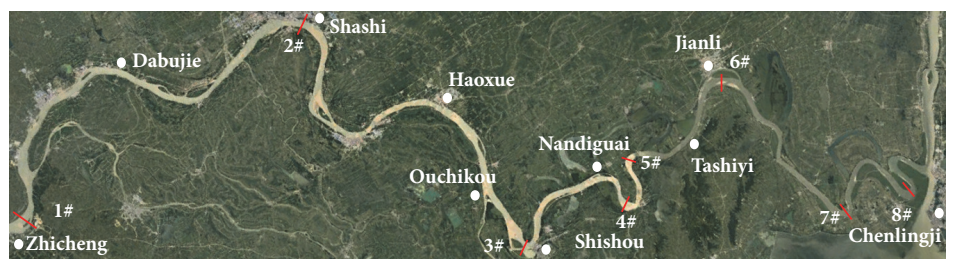

(a) Section position map

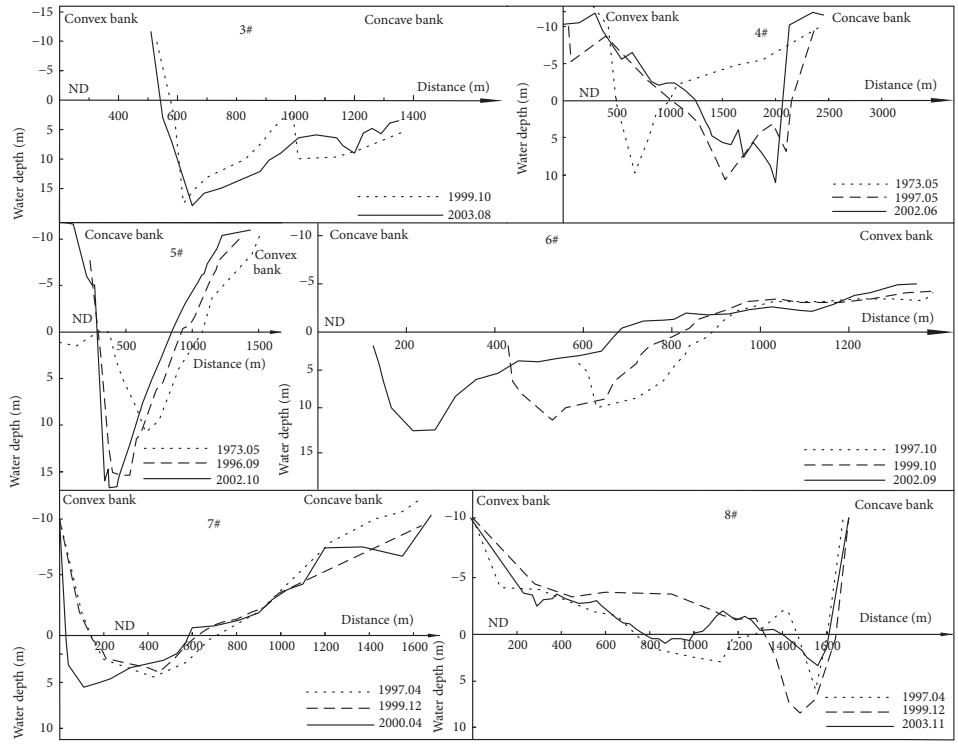

(b) Cross section change before impoundment of the Three Gorges Reservoir

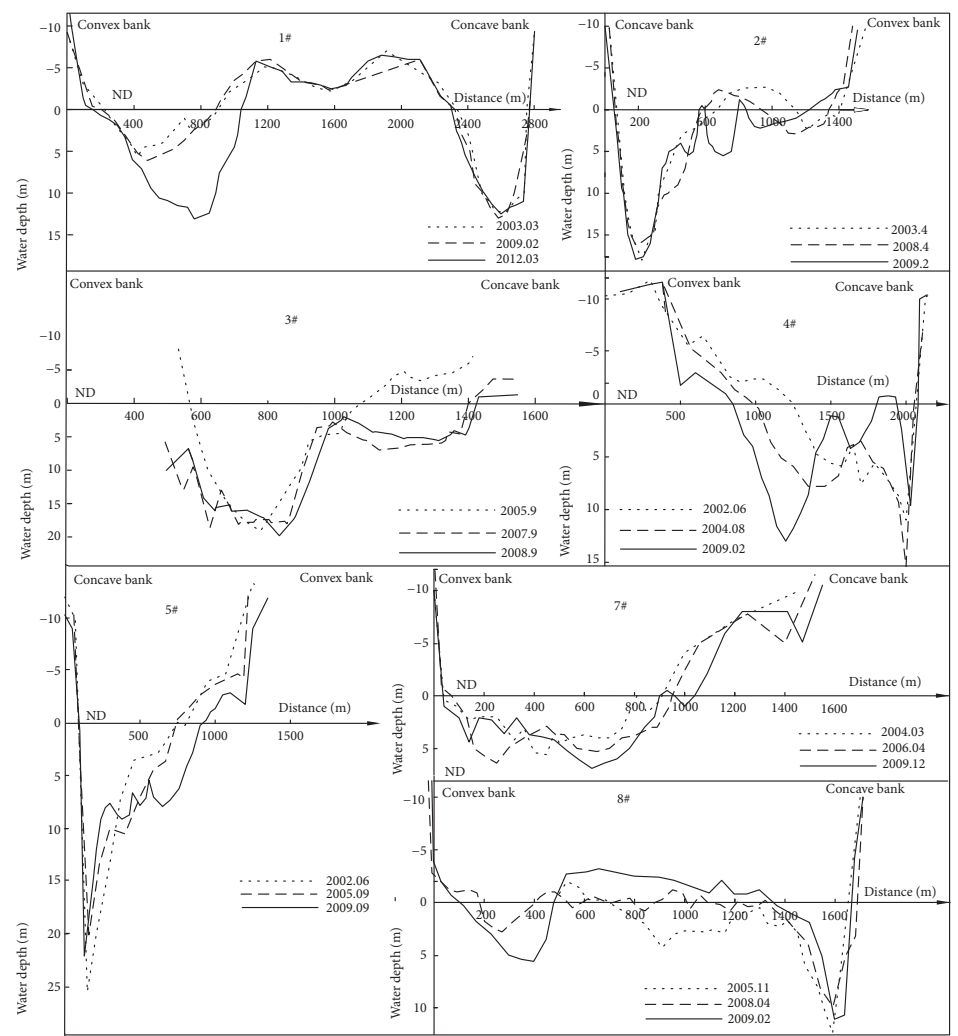

(c) Cross section change after impoundment of the Three Gorges Reservoir

FIGURE 3: Cross section change of curving reaches in Jingjiang river. 


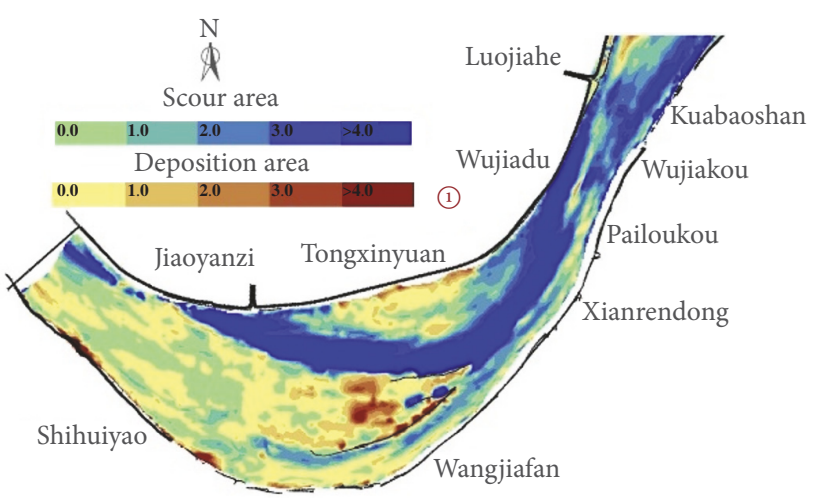

FIGURE 4: Erosion and siltation distribution of (1)Guanzhou CR (2003.02 2012.02).

Faizui CR, and Xingjiazhou CR, shown as Figures 3(a) and 3(c).

Taking Guanzhou CR (a typical Type A reach) for instance, bed near convex bank had been scoured obviously and bed near concave bank had been deposited obviously after impounding of TGR, for the average depth of scouring grooves were $5 \mathrm{~m}$, and $3 \mathrm{~m}$ for depositing area near concave bank, shown as Figure 4. The distributary ratios of convex at Guanzhou CR changed from $19.07 \%$ (at year 2003) to $34.08 \%$ (at year 2012).

As well as (9)Tiaoguan CR, its convex bank (named Jijiazui beach) was scoured badly; the average scouring depth was more than $5 \mathrm{~m}$, shown as Figure 5. Its maximum distance of zero-meter isobath wentting to the convex bank were 230m (2003 2006) and 420m (2006 2009). The zero-meter isobath area decreased from $1.88(\mathrm{~km})^{2}(2002)$ to $0.56(\mathrm{~km})^{2}$ (2009), shrinking almost two thirds. Because of the scouring effect, the area of Jijiazui beach became smaller and smaller. Therefore, water flow in (9Tiaoguan CR got diminishing constraint, tended to go straight along the river channel, which made the nearby concave bank (Xiaojiaguai) became deposited. There had been an obvious sediment deposition in nearby concave bank in August, 2009, and it became a diara in August, 2014. In the following years, the diara is steady and divides the main river channel into two channels in low water period, shown as Figure 6.

(2) Type B has kept its appearance but accelerates its speed or aggravate its level, such as Wakouzi CR, Majiazui CR and Qigongling CR; Distributary ratios near convex bank at Wakouzi CR and Majiazui CR has been increased; Little channeling groove near convex bank at Qigongling CR and Guanyinzhou CR has been developed, even separates the beach into two parts.

Taking Qigongling CR (a typical Type B reach) for instance, the convex bank already be scoured and resulted in little channeling grooves before impounding of TGR; and then the beach became shrunken rapidly and the grooves became extended rapidly after the TGR impounding water, shown as Figure 7. From Tables 1 and 2, beach area at the convex bank was $1.7(\mathrm{~km})^{2}$ (at year 2004) but dropped to 0.28 $(\mathrm{km})^{2}$ (at year 2012). The river island area at the concave bank
TABLE 1: The geometric appearance of the convex beach at Qigongling CR (the length/width is the maximum value of the beach).

\begin{tabular}{lccc}
\hline Measured time & Area $\left(\mathrm{km}^{2}\right)$ & Length $(\mathrm{m})$ & Width $(\mathrm{m})$ \\
\hline 2006.04 .23 & 1.70 & 3616 & 662 \\
2007.04 .24 & 0.75 & 2333 & 394 \\
2009.03 .29 & 0.48 & 1236 & 454 \\
2009.09 .06 & 0.43 & 1181 & 385 \\
2009.11 .13 & 0.28 & 892 & 377 \\
2012.02 .15 & 0.28 & 912 & 184 \\
\hline
\end{tabular}

TABLE 2: The geometric appearance of the river island at Qigongling $\mathrm{CR}$ (the length/width is the maximum value of the river island).

\begin{tabular}{lccc}
\hline Measured time & Area $\left(\mathrm{km}^{2}\right)$ & Length $(\mathrm{m})$ & Width $(\mathrm{m})$ \\
\hline 2004.03 .12 & 0.11 & 1300 & 120 \\
2006.04 .23 & 1.19 & 5858 & 354 \\
2007.04 .24 & 1.79 & 6482 & 533 \\
2009.03 .29 & 2.31 & 3481 & 866 \\
2009.09 .06 & 2.16 & 3297 & 873 \\
2009.11 .13 & 1.69 & 2355 & 1139 \\
2012.02 .15 & 1.92 & 3520 & 850 \\
\hline
\end{tabular}

was $0.07(\mathrm{~km})^{2}$ (at year 2004) but soared to $1.92(\mathrm{~km})^{2}$ (at year 2012).

\section{Two-Dimensional Model}

The evolution disciplines of curved reaches were complex. To improve the analysis accuracy, a two-dimensional (2D) numerical model was built. The model was verified by the measured data and used to study the evolution disciplines of curved reaches.

3.1. Fundamental Equations. A pane two-dimensional mathematical model was use to simulated the river $[19,20]$. The transformation of normal curve equations was shown as follows from (1) to (3).

Flow continuous equation is

$$
J \frac{\partial Z}{\partial t}+\frac{\partial H U}{\partial \zeta}+\frac{\partial H V}{\partial \eta}=0
$$

where J was water surface slope; $Z$ was water level, $\mathrm{m} ; H$ is water depth, $\mathrm{m}$; $U$ was velocity in $\mathrm{X}$ direction, $\mathrm{m} / \mathrm{s} ; \mathrm{V}$ was velocity in $\mathrm{X}$ direction, $\mathrm{m} / \mathrm{s} ; \xi$ was direction of river mainstream; $\eta$ was direction of river width.

Flow motion equation is

$$
\begin{aligned}
J \frac{\partial M}{\partial t} & +\frac{\partial M U}{\partial \zeta}+\frac{\partial M V}{\partial \eta} \\
= & -g h J\left(\xi_{x} \frac{\partial Z}{\partial \zeta}+\eta_{x} \frac{\partial Z}{\partial \eta}\right) \\
& +\frac{\partial}{\partial \zeta}\left[D J\left(q_{11} M_{\zeta}+q_{12} M_{\eta}\right)\right]
\end{aligned}
$$




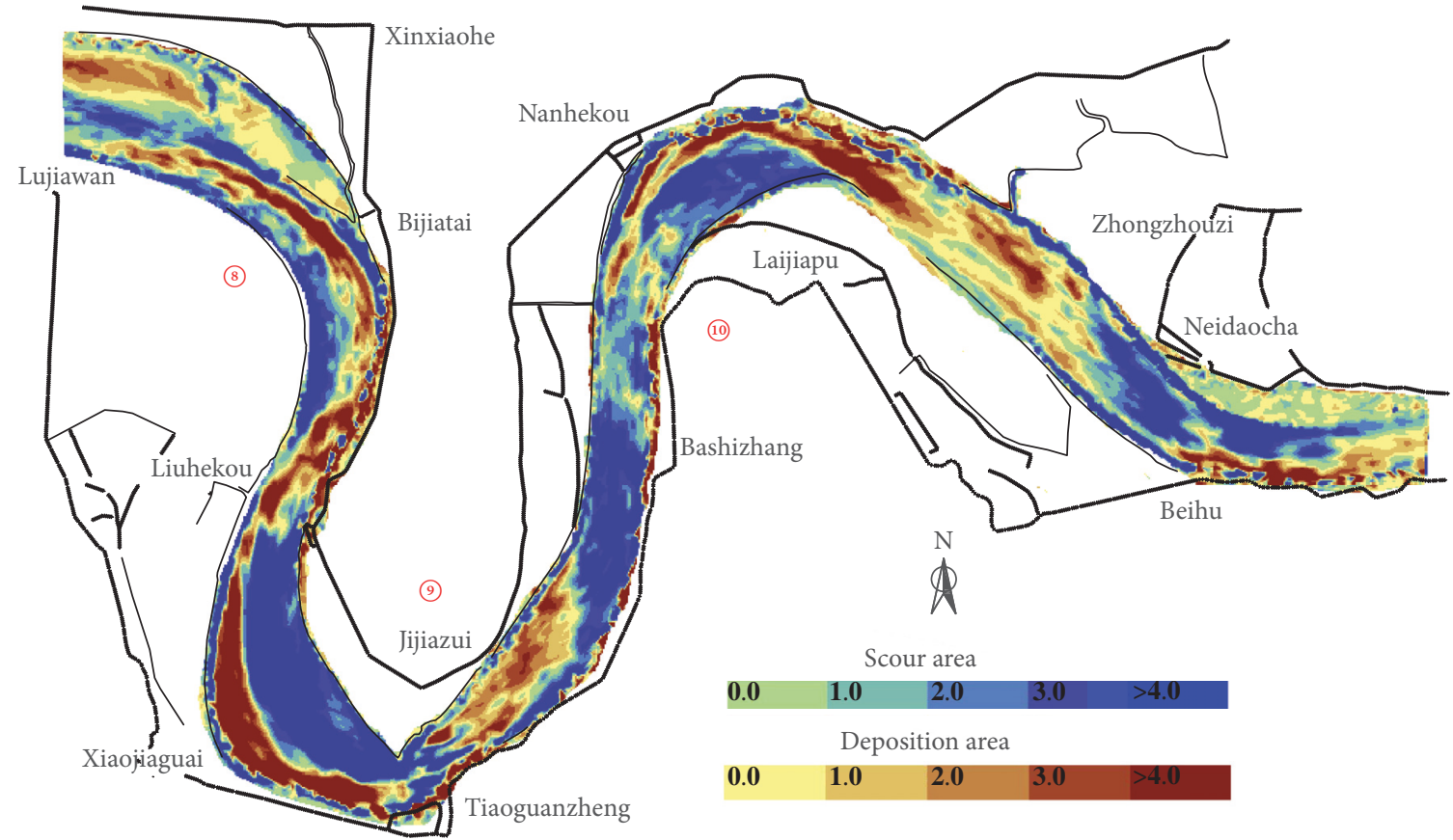

FIGURE 5: Erosion and siltation distribution of (9Tiaoguan CR (2002.10 2009.09).

(1) Guanzhou CR (2003.02 2012.02)

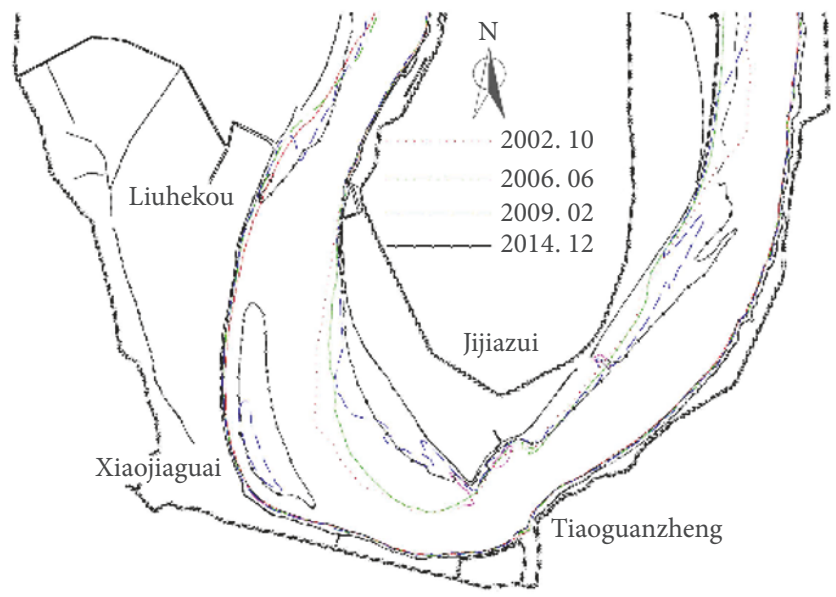

(a)

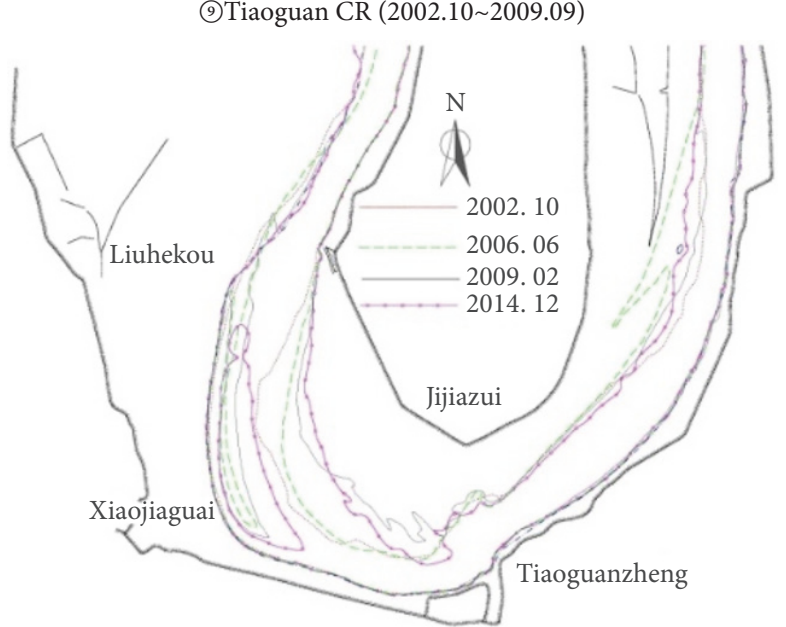

(b)

FIGURE 6: Isobath variation in (9Tiaoguan CR. (a) zero-meter and (b) four-meter.

$$
\begin{aligned}
& +\frac{\partial}{\partial \eta}\left[D J\left(q_{12} M_{\zeta}+q_{22} M_{\eta}\right)\right] \\
& -\frac{g n^{2} M \sqrt{u^{2}+v^{2}}}{h^{4 / 3}} J
\end{aligned}
$$

where $M$ and $N$ were discharged per unit width in $x$ and $y$ direction separately, $M=u h$ and $N=v h ; n$ was Manning Roughness Coefficient; $g$ was gravity acceleration, $\mathrm{m} / \mathrm{s}^{2} ; D$ was Turbulent Viscosity Coefficient, $L^{2} T^{-1} ; \xi_{x}, \eta_{x}, \xi_{y}$, and $\eta_{y}$ were the conversion coefficient of $\mathrm{X}-\xi, \mathrm{X}-\eta, \mathrm{Y}-\xi$, and
$\mathrm{Y}-\eta \cdot q_{11}=\xi_{x}^{2}+\xi_{y}^{2}, q_{12}=\xi_{x} \eta_{x}+\xi_{y} \eta_{y}$, and $q_{22}=\eta_{x}^{2}+\eta_{y}^{2}$; $M_{x}, M_{y}, N_{x}$, and $N_{y}$ were partial derivative, as $M_{x}$ was $M$ 's partial derivative in $\mathrm{X}$ direction.

Motion equation of the water goes vertically along the river channel:

$$
\begin{aligned}
J \frac{\partial N}{\partial t}+\frac{\partial N U}{\partial \zeta} \frac{\partial N V}{\partial \eta}= & -g h J\left(\zeta_{y} \frac{\partial Z}{\partial \zeta}+\eta_{y} \frac{\partial Z}{\partial \eta}\right) \\
& +\frac{\partial}{\partial \zeta}\left[D J\left(q_{11} N_{\zeta}+q_{12} N_{\eta}\right)\right]
\end{aligned}
$$




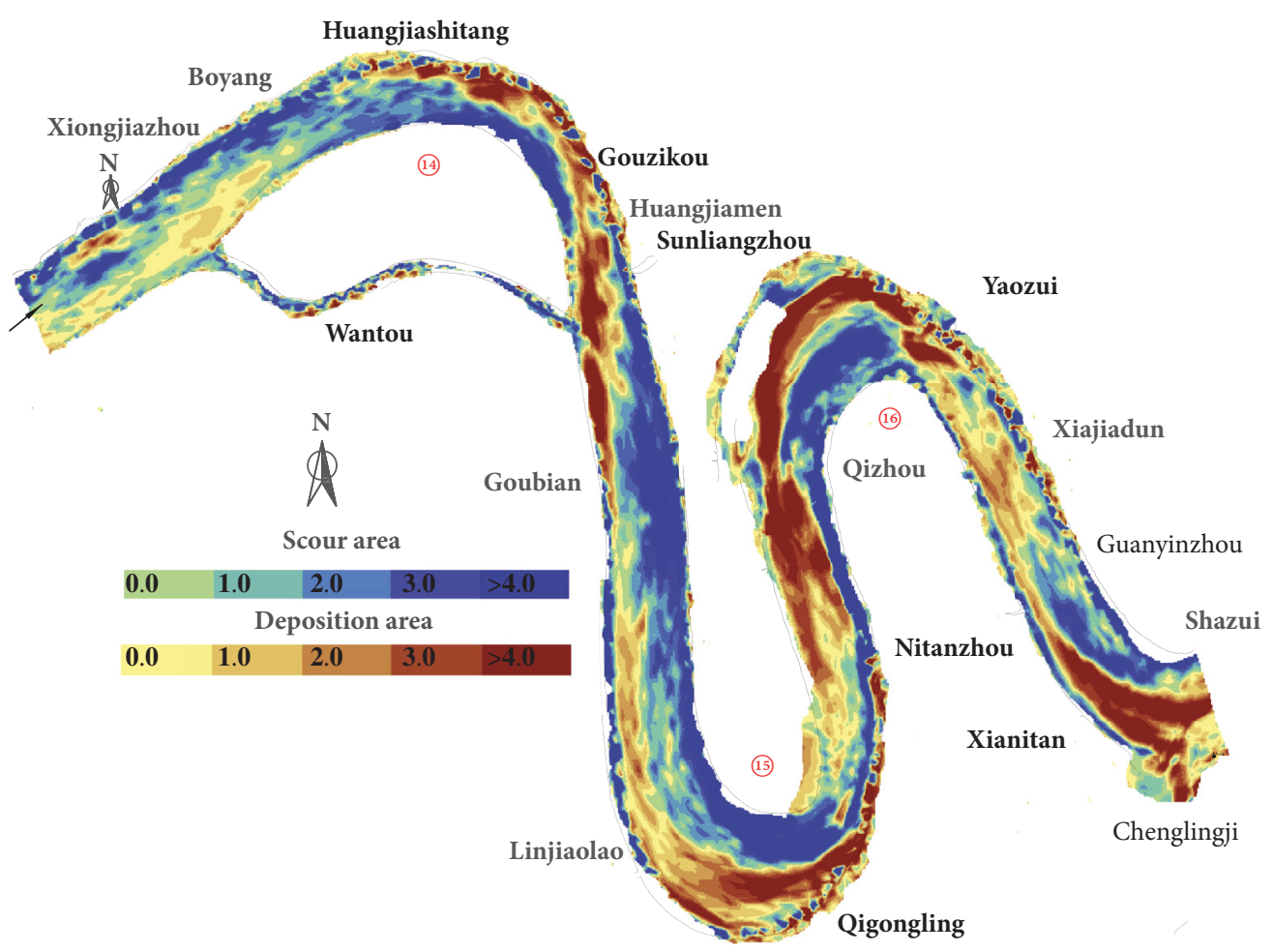

FIGURE 7: Erosion and siltation distribution of (14) Xiongjiazhou CR, (15) Qigongling CR, and (16) Guanyingzhou CR (2002.02 2010.02).

$$
\begin{aligned}
& +\frac{\partial}{\partial \eta}\left[D J\left(q_{12} N_{\zeta}+q_{22} N_{\eta}\right)\right] \\
& -\frac{g n^{2} N \sqrt{u^{2}+v^{2}}}{h^{4 / 3}} J
\end{aligned}
$$

3.2. Roughness Factor. The channel bed resistance includes sand-grain resistance, sand-wave resistance, bed configuration resistance, and settled deposit resistance. Sections of Jingjiang channel were wide and deep, and channel bed was made of sand. An empirical equation for roughness factor is chosen as

$$
n=C_{1} \cdot\left(1+\left(\frac{1}{h}\right)^{n_{1}}\right) \cdot f(A, r, u)
$$

where $n$ is roughness factor of the river channel; $C_{1}$ is unidimensional roughness factor; $h$ is water depth; $n_{1}$ is roughness factor of the across section; $A$ is water flow area; $r$ is radius curvature; $u$ is current velocity; $f(A, r, u)$ is the plane morphological function of the river; the value is generally between 0.5 and 1.5 [21].

3.3. Computational Meshes. The computational results of $2 \mathrm{D}$ model will be used to simulate the boundary conditions of $3 \mathrm{D}$ model, while the boundary conditions of 2D model are obtained from the observed data and its interpolation results. Taking Nandiguai-Tashiyi reach (including Hekou CR, Tiaoguan CR and Laijiapu CR) and Tashiyi-Chenglingji reach (including Jianli CR, Tianxingge CR, Fanzui CR, Xiongjiazhou CR, Qigongling CR, Guanyingzhou CR) for instances, the mesh details are as follows:

(1) Tianguan-Tashiyi Reach. Nandiguai-Tashiyi reach begins at Nandiguai and ends at Tashiyi, while the total length is $37 \mathrm{~km}$. The meshed model is shown as Figure 8, and there are a total of $520 \times 120$ grid points. The type of the grid is calculated from Elliptic differential equations [22]; along the river channel there are 520 grid points and the distance between every two grid points is $40 \sim 100 \mathrm{~m}$; furthermore, perpendicular to the river channel there are 100 grid points and the distance between every two grid points is $10 \sim 20 \mathrm{~m}$.

(2) Tashiyi-Chenglingji Reach. Tashiyi-Chenglingji reach begins at Tashiyi and ends at Chenglingji, while the total length is $96 \mathrm{~km}$. The meshed model is shown as Figure 9, and there are a total of $900 \times 80$ grid points. The type of the grid is the orthogonal curvilinear coordinate mesh [23]; along the river channel there are 900 grid points and the distance between every two grid points is $67 \sim 144 \mathrm{~m}$; furthermore, perpendicular to the river channel there are 80 grid points and the distance between every two grid points is $5 \sim 40 \mathrm{~m}$.

\subsection{Verification}

3.4.1. Verification of Fixed Bed Model. River toughness factor and sand transport capacity are calibrated according to the 


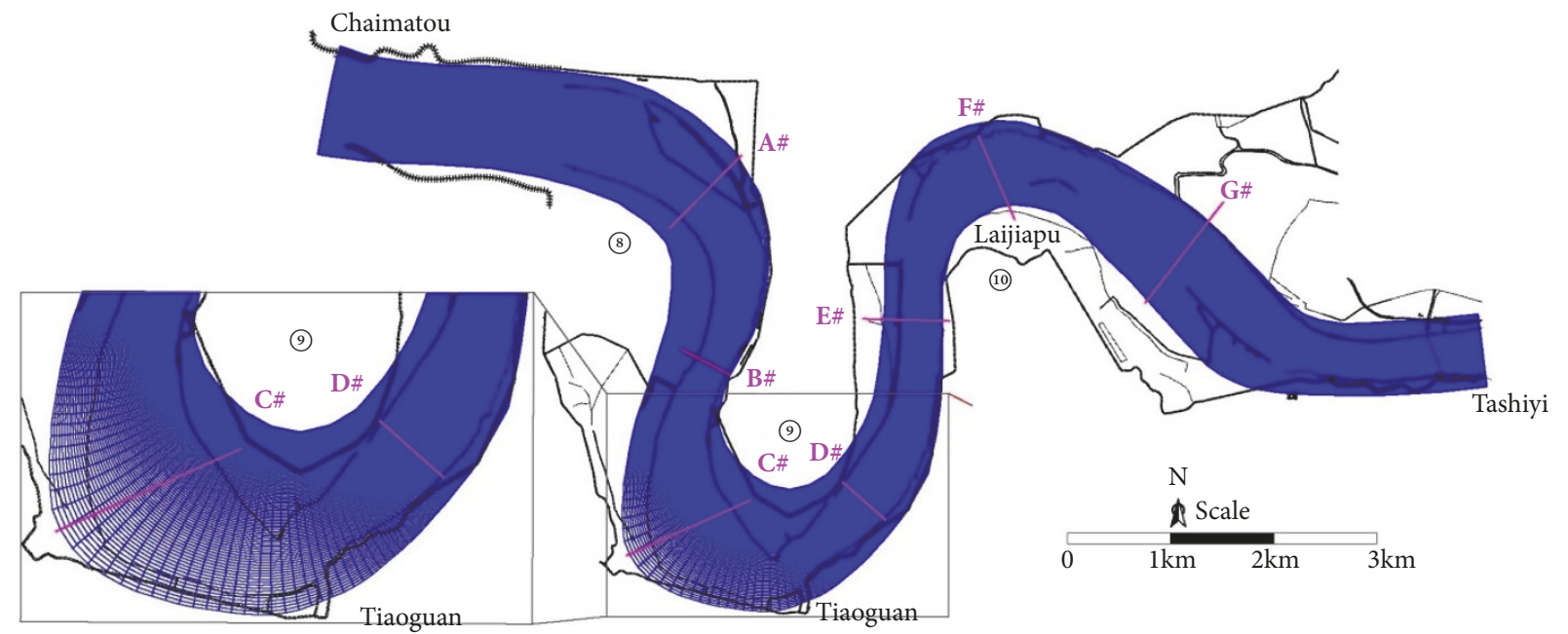

Figure 8: Mesh details of Nandiguai-Tashiyi reach.

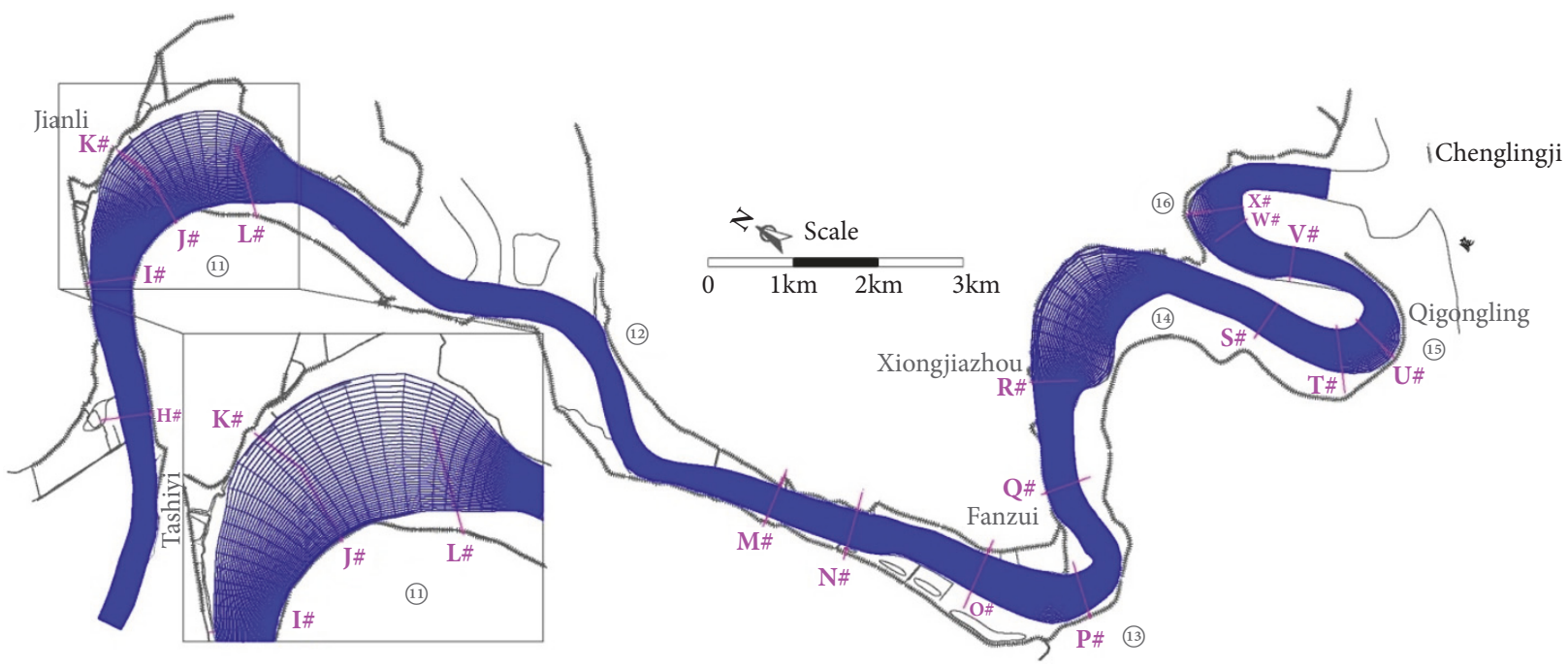

FIGURE 9: Mesh details of Tashiyi-Chenglingji reach.

measured data, including water level, distributary ratio of branch, current velocity distribution, and river scouring and depositing amount.

(1) Water Level. Water levels at different locations are calculated by the 2D model at flood period, median water period, and drought period, respectively. With the measured data, the calculating results are shown in Tables 3, 4, and 5 accordingly. All of the water level errors are less than $0.11 \mathrm{~m}$. Predicted water level displays a reasonable agreement with measured data.

(2) Distributary Ratio of Branch. Jianli CR as Figure 10, a typical branching curve, is chosen to validate distributary ratio of the model. Distributary ratios in Jianli CR were calculated by the 2D model at flood period (July 2007, Q=28900 $\mathrm{m} 3 / \mathrm{s}$ ), median water period (Oct, 2008, Q=16322m3/s; Sep, 2010, $\mathrm{Q}=19175 \mathrm{~m} 3 / \mathrm{s}$ ), and drought period, respectively (Jan $2006,5231 \mathrm{~m} 3 / \mathrm{s})$. From the results, the calculated values of each branch diversion ratio are in good agreement with the measured values and errors are within $2 \%$. Results show that the model can reflect variation of branch diversion and meet the requirement of calculation. The split ratio verification is shown in Table 6.

(3) Flow Velocity Distribution Verification. Calculated flow velocity values in different curved reach are vivificated by 
TABLE 3: Water level at flood period ( $Q$ is flow rate, $h_{m}$ is measured value, $h_{p}$ is predicted value, and $\gamma_{h}$ is error, $\left.\gamma_{h}=h_{p}-h_{m}\right)$.

\begin{tabular}{|c|c|c|c|c|c|c|c|c|c|}
\hline \multirow{3}{*}{$\begin{array}{l}\text { Section } \\
\text { location }\end{array}$} & \multicolumn{3}{|c|}{ Jianli CR @ July, 2007} & \multicolumn{3}{|c|}{ Fanzui CR @ Aug, 2010} & \multicolumn{3}{|c|}{ Tiaoguan CR @Sep, 2010} \\
\hline & \multicolumn{3}{|c|}{$Q=28900 \mathrm{~m}^{3} / \mathrm{s}$} & \multicolumn{3}{|c|}{$Q=20444 \mathrm{~m}^{3} / \mathrm{s}$} & \multicolumn{3}{|c|}{$Q=19735 \mathrm{~m}^{3} / \mathrm{s}$} \\
\hline & $\begin{array}{l}h_{m} \\
(\mathrm{~m})\end{array}$ & $\begin{array}{c}h_{c} \\
(\mathrm{~m})\end{array}$ & $\begin{array}{l}\gamma_{h} \\
(\mathrm{~m})\end{array}$ & $\begin{array}{l}h_{m} \\
(\mathrm{~m})\end{array}$ & $\begin{array}{l}h_{c} \\
(\mathrm{~m})\end{array}$ & $\begin{array}{l}\gamma_{h} \\
(\mathrm{~m})\end{array}$ & $\begin{array}{l}h_{m} \\
(\mathrm{~m})\end{array}$ & $\begin{array}{c}h_{c} \\
(\mathrm{~m})\end{array}$ & $\begin{array}{l}\gamma_{h} \\
(\mathrm{~m})\end{array}$ \\
\hline $1 \# \mathrm{~L}$ & 31.46 & 31.5 & 0.04 & 29.02 & 29.00 & -0.02 & 32.15 & 32.16 & 0.00 \\
\hline $2 \# \mathrm{~L}$ & 31.26 & 31.37 & 0.11 & 28.88 & 28.86 & -0.02 & 31.92 & 31.94 & 0.02 \\
\hline $3 \# \mathrm{~L}$ & 31.1 & 31.1 & 0.00 & 28.70 & 28.67 & -0.03 & 31.77 & 31.78 & 0.01 \\
\hline $4 \# \mathrm{~L}$ & 31.1 & 31.1 & 0.00 & 28.50 & 28.51 & 0.01 & 31.62 & 31.62 & 0.00 \\
\hline $5 \# \mathrm{~L}$ & 30.99 & 30.97 & -0.02 & 28.35 & 28.40 & 0.05 & 31.46 & 31.43 & -0.03 \\
\hline $6 \# \mathrm{~L}$ & l & l & l & 28.15 & 28.16 & 0.01 & 31.33 & 31.29 & -0.04 \\
\hline $7 \# \mathrm{~L}$ & l & l & 1 & I & I & 1 & 31.04 & 31.02 & -0.02 \\
\hline
\end{tabular}

TABLE 4: Water level at median water period.

\begin{tabular}{|c|c|c|c|c|c|c|}
\hline \multirow{2}{*}{$\begin{array}{l}\text { Section } \\
\text { location }\end{array}$} & \multicolumn{3}{|c|}{$\begin{array}{l}\text { Jianli CR @ Oct, } 2008 \\
\qquad Q=16322 \mathrm{~m}^{3} / \mathrm{s}\end{array}$} & \multicolumn{3}{|c|}{$\begin{array}{l}\text { Fanzui CR @ Sep, } 2009 \\
\qquad Q=14232 \mathrm{~m}^{3} / \mathrm{s}\end{array}$} \\
\hline & $\begin{array}{l}h_{m} \\
(\mathrm{~m})\end{array}$ & $\begin{array}{l}h_{c} \\
(\mathrm{~m})\end{array}$ & $\begin{array}{l}\gamma_{h} \\
(\mathrm{~m})\end{array}$ & $\begin{array}{l}h_{m} \\
(\mathrm{~m})\end{array}$ & $\begin{array}{l}h_{c} \\
(\mathrm{~m})\end{array}$ & $\begin{array}{l}\gamma_{h} \\
(\mathrm{~m})\end{array}$ \\
\hline $1 \# \mathrm{~L}$ & 29.45 & 29.48 & 0.03 & 27.12 & 27.18 & 0.06 \\
\hline $2 \# \mathrm{~L}$ & 29.33 & 29.33 & 0.00 & 26.99 & 27.05 & 0.06 \\
\hline 3\#L & 1 & I & I & 26.84 & 26.88 & 0.04 \\
\hline $4 \# \mathrm{~L}$ & 29.21 & 29.22 & 0.01 & 26.69 & 26.66 & -0.03 \\
\hline $5 \# \mathrm{~L}$ & 28.92 & 28.87 & -0.05 & 26.62 & 26.58 & -0.04 \\
\hline 7\#L & & & & 26.42 & 26.37 & -0.05 \\
\hline
\end{tabular}

TABLE 5: Water level at drought period.

\begin{tabular}{|c|c|c|c|c|c|c|c|c|c|}
\hline \multirow{3}{*}{$\begin{array}{l}\text { Section } \\
\text { location }\end{array}$} & \multicolumn{3}{|c|}{ Jianli CR@ Jun, 2006} & \multicolumn{3}{|c|}{ Qigongling CR @ Feb, 2012} & \multicolumn{3}{|c|}{ Tiaoguan CR @ Feb, 2014} \\
\hline & & $\mathrm{Q}=5231$ & & & $Q=62$ & & & $Q=651$ & \\
\hline & $\begin{array}{l}h_{m} \\
(\mathrm{~m})\end{array}$ & $\begin{array}{c}h_{c} \\
(\mathrm{~m})\end{array}$ & $\begin{array}{l}\gamma_{h} \\
(\mathrm{~m})\end{array}$ & $\begin{array}{l}h_{m} \\
(\mathrm{~m})\end{array}$ & $\begin{array}{l}h_{c} \\
(\mathrm{~m})\end{array}$ & $\begin{array}{l}\gamma_{h} \\
(\mathrm{~m})\end{array}$ & $\begin{array}{l}h_{m} \\
(\mathrm{~m})\end{array}$ & $\begin{array}{c}h_{c} \\
(\mathrm{~m})\end{array}$ & $\begin{array}{l}\gamma_{h} \\
(\mathrm{~m})\end{array}$ \\
\hline $1 \# \mathrm{~L}$ & 23.11 & 23.17 & 0.06 & 29.02 & 29.00 & -0.02 & 24.40 & 24.41 & -0.01 \\
\hline $2 \# \mathrm{~L}$ & 22.94 & 22.96 & 0.02 & 28.88 & 28.86 & -0.02 & 24.19 & 24.20 & -0.01 \\
\hline $3 \# \mathrm{~L}$ & 22.57 & 22.52 & -0.05 & 28.70 & 28.67 & -0.03 & 24.06 & 24.08 & -0.02 \\
\hline $4 \# \mathrm{~L}$ & 22.22 & 22.25 & 0.04 & 28.50 & 28.51 & 0.01 & 23.99 & 23.98 & 0.01 \\
\hline $5 \# \mathrm{~L}$ & 22.14 & 22.14 & 0 & 28.35 & 28.40 & 0.05 & 23.84 & 23.83 & 0.01 \\
\hline $6 \# \mathrm{~L}$ & 23.11 & 23.17 & 0.06 & 28.15 & 28.16 & 0.01 & 23.68 & 23.71 & -0.03 \\
\hline 7\#L & 1 & l & l & 1 & 1 & I & 23.51 & 23.56 & -0.05 \\
\hline
\end{tabular}

TABLE 6: Distributary ratio at different flow rate $\left(\varphi_{m}\right.$ is measured value, $\varphi_{p}$ is predicted value, and $\gamma_{\varphi}$ is error, $\left.\gamma_{\varphi}=\varphi_{p}-\varphi_{m}\right)$.

\begin{tabular}{lcccccccc}
\hline & \multirow{2}{*}{$\left(\mathrm{m}^{3} / \mathrm{s}\right)$} & \multirow{2}{*}{ Date } & \multicolumn{3}{c}{ Left branch } & \multicolumn{3}{c}{ Right branch } \\
& & & $\varphi_{m}(\%)$ & $\varphi_{p}(\%)$ & $\gamma_{\varphi}(\%)$ & $\varphi_{m}(\%)$ & $\varphi_{p}(\%)$ & $\gamma_{\varphi}(\%)$ \\
\hline Low water period & 5231 & 2006.01 & 3.76 & 3.14 & -0.62 & 96.24 & 96.86 \\
\hline \multirow{2}{*}{ Median water period } & 16322 & 2008.10 & 8.50 & 10.36 & 1.86 & 91.50 & 89.64 & -1.86 \\
& 19175 & 2010.09 & 10.77 & 10.22 & -0.55 & 89.23 & 89.78 & 0.55 \\
\hline High water period & 28900 & 2007.07 & 8.96 & 8.02 & -0.94 & 91.04 & 91.98 & 0.94 \\
\hline
\end{tabular}




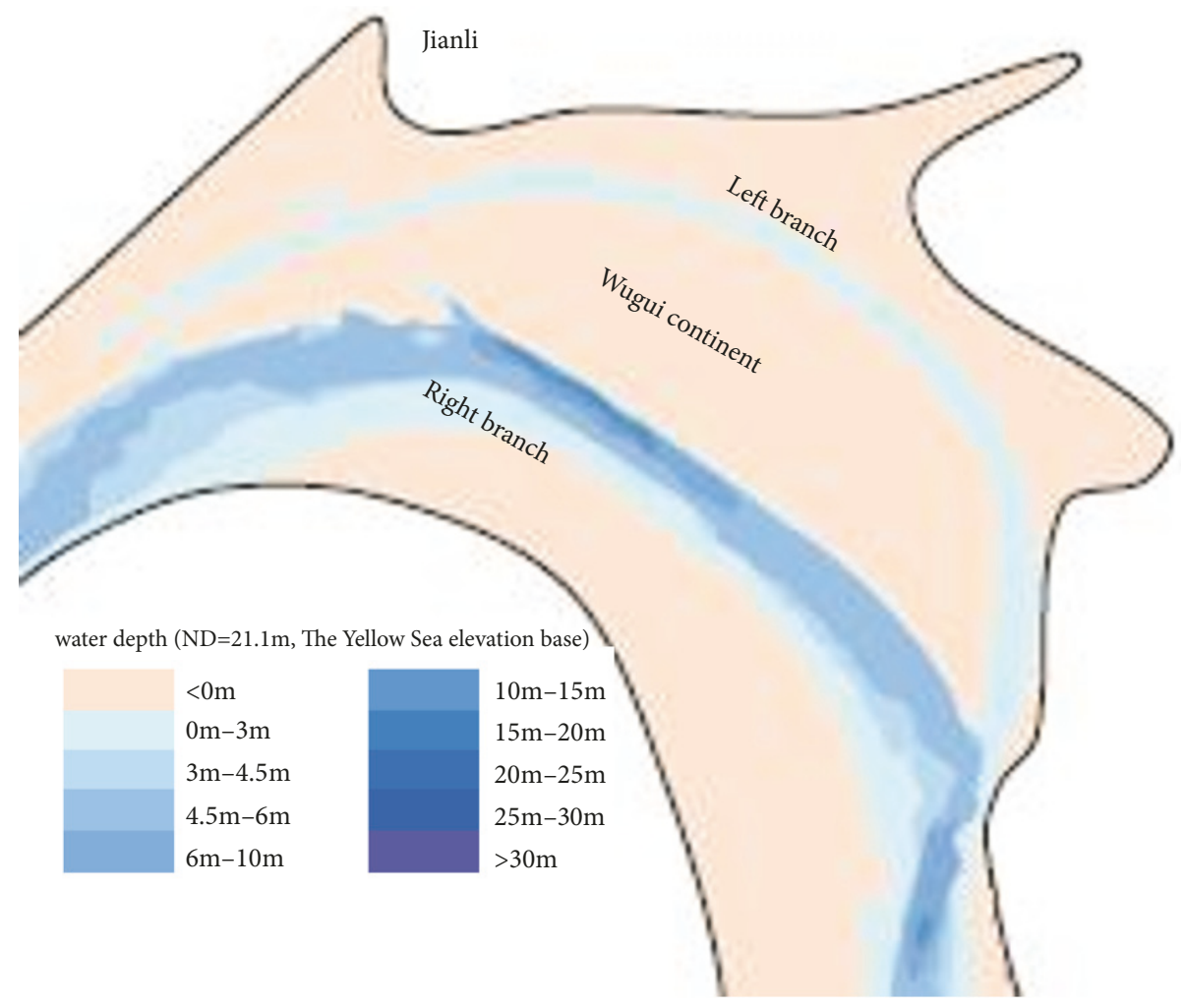

FIGURE 10: Sketch map of Jianli CR (December, 2014).

TABLE 7: Comparison of depositing and scouring amount in selected reaches (from 2010.3 to 2012.2). ( $\alpha$ is the measured data, $\beta$ is the calculated value, positive values mean depositing, and minus values mean scouring. $\gamma$ is the relative error, $\gamma=(\beta-\alpha) / \alpha \times 100 \%)$.

\begin{tabular}{lccc}
\hline Reach name & $\begin{array}{c}\alpha \\
\left(\times 10^{4} \mathrm{~m}^{3}\right)\end{array}$ & $\begin{array}{c}\beta \\
\left(\times 10^{4} \mathrm{~m}^{3}\right)\end{array}$ \\
\hline Tiaoguan CR & 163.4 & 185.4 & 13.46 \\
Laijiapu CR & 351.9 & 303.8 & -13.67 \\
Tashiyi to Hongshuigang reach & -549.58 & -485.03 & -11.7 \\
Yanchuantao to Jingjiangmen reach & -1030.35 & -873.62 & -15.2 \\
Xiongjiazhou to Chenglingji reach & 855.98 & 758.24 & -11.4 \\
\hline
\end{tabular}

measured values. Typical sections in Tiaoguan CR and Laijiapu CR are chosen; comparison diagram with calculated values and measured values are drew in Figure 11. All of the errors between measured value and measured values are less than $0.2 \mathrm{~m} / \mathrm{s}$, and the model meets the requirements of flow velocity simulation.

3.4.2. Verification of Moving Bed Model. According to the field testing points, reaches listed in Table 6 are selected to compare the measured and calculated variable quantity of sediment. The geomorphic features in March, 2010 are set as the boundary conditions for the $2 \mathrm{D}$ numerical model; the incoming sediment and water are considered as extra loading. Table 7 shows that the $2 \mathrm{D}$ numerical model has a reasonable accuracy, for the maximum error is $15.2 \%$. Therefore, the $2 \mathrm{D}$ numerical model can be used as a technique to study the dynamic evolution disciplines downstream of the TGD.

\section{Three-Dimensional Model}

The 2D model could describe the plant evolution disciplines of curved reaches. For curved reaches with strong threedimensional characteristics, 2D model could not describe the vertical characteristic of water and sediment. Thus, a superior three-dimensional (3D) numerical model was built to analyze the water and sediment movement characteristic. The $3 \mathrm{D}$ model's boundary conditions were given by the results of the 

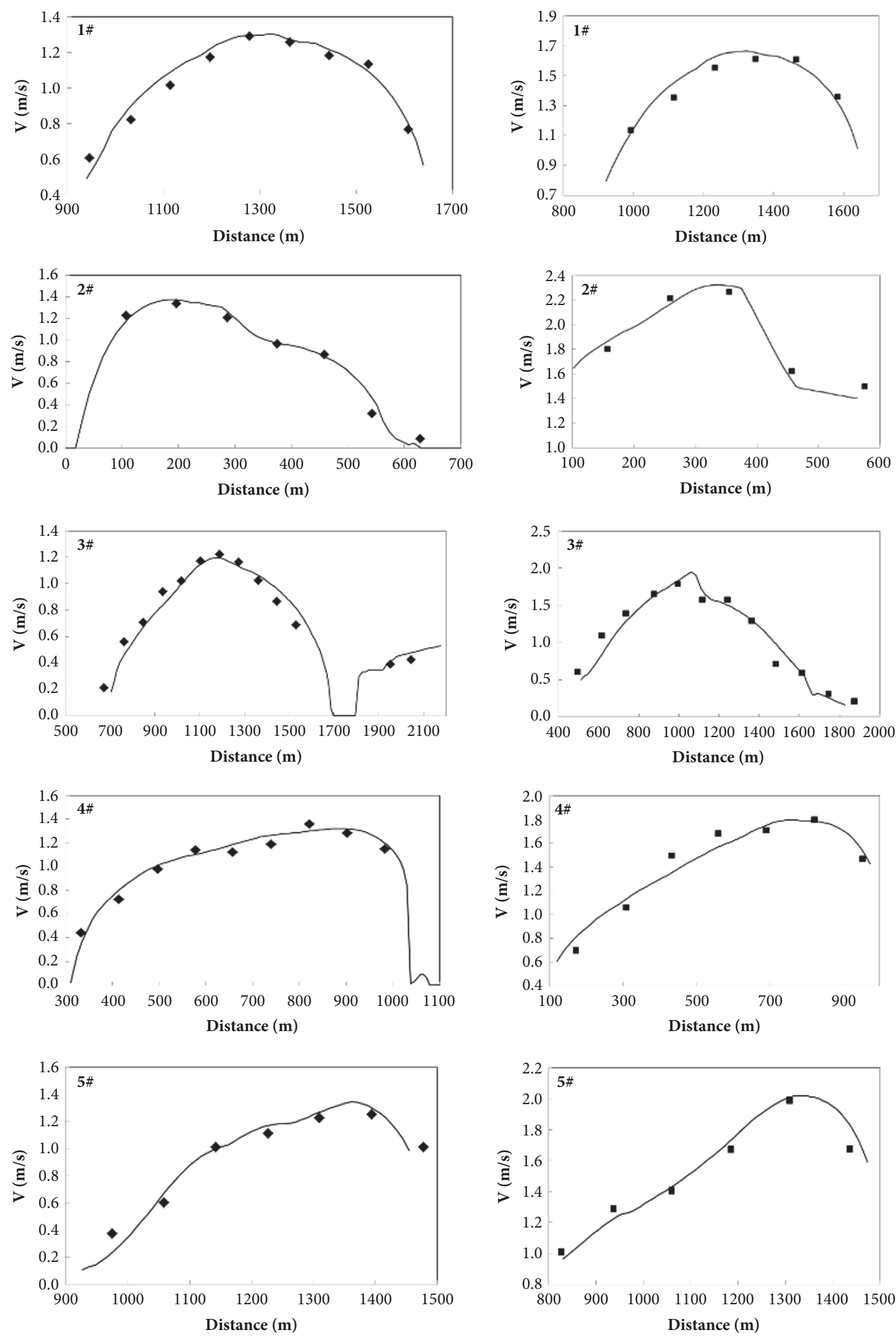

(a)

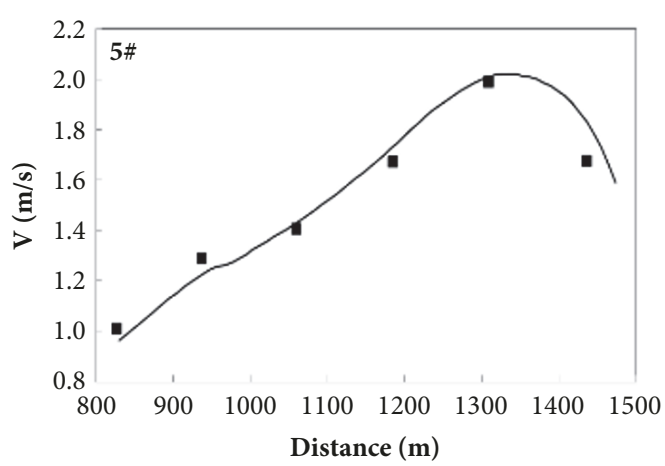

(b)

FIGURE 11: Cross section velocity verification of Tiaoguan CR on December, 2014 ( — calculated value, $\mathbf{m e a s u r e d ~ d a t a ) : ~ ( a ) ~ Q = 7 6 3 3 ~} \mathrm{m}^{3} / \mathrm{s}$; (b) $\mathrm{Q}=19263 \mathrm{~m}^{3} / \mathrm{s}$, 
2D numerical model. The two models were verified by the measured data, and part of results by $3 \mathrm{D}$ model was also verified by $2 \mathrm{D}$ model.

\subsection{Fundamental Equations}

4.1.1. Water Flow Equation. The three-dimensional (3D) water flow equation in the Cartesian coordinate system is (5), and Navier-Stokes equation [24] is (6):

$$
\begin{aligned}
\frac{\partial u_{i}}{\partial x_{i}} & =0 \\
\rho \frac{d u}{d t} & =-\frac{\partial P}{\partial x_{i}}+P X_{i}+\mu \Delta u_{i}
\end{aligned}
$$

where $x_{i}$ is the coordinate axis of the system; $\rho$ is fluid density; $\mathrm{P}$ is water pressure; $u_{i}$ is water current velocity; $\mu$ is water dynamic viscosity coefficient (generally equal to $1 \times$ $10^{-6} \mathrm{~m}^{2} \sec ^{-1}$ ).

For the Large Eddy Simulation (LES) model [25], the physical variable should be factorized into large scale pulsation and small scale pulsation after the fundamental equation done the space-filtering operation. For example, $f$ is a $3 \mathrm{D}$ physical variable; differential operator of $f$ can be spacefiltering operated as

$$
\begin{gathered}
\frac{\overline{\partial f(x)}}{\partial x}=\frac{\partial \overline{f(x)}}{\partial x} \\
\frac{\overline{\partial^{n} f(x)}}{\partial x^{n}}=\frac{\partial^{n} \overline{f(x)}}{\partial x^{n}}
\end{gathered}
$$

Equations (7) and (8), Smagorinsky pattern [26, 27], and Space filtering operation (9) are used to solve (5) and (6); therefore (10a)-(10g) were achieved:

$$
\begin{aligned}
\overline{\bar{f}} & \neq \bar{f} \\
\overline{\bar{f}} \bar{g} & \neq \bar{f} \bar{g} \\
\overline{\bar{f} g^{\prime}} & \neq 0 \\
\frac{\partial \overline{u_{i}}}{\partial x_{i}} & =0 \\
\frac{\partial \overline{u_{i}}}{\partial t} & =-\frac{1}{\rho} \frac{\partial P}{\partial x_{i}}-\frac{\partial\left(\overline{u_{i}} \overline{u_{j}}\right)}{\partial x_{j}}+\frac{\partial}{\partial x_{j}}\left(2 v_{e} \overline{S_{i j}}\right)+g_{i} \\
v_{e} & =v+v_{t} \\
v_{t} & =\left(C_{s} \Delta\right)^{2}\left(2 \overline{S_{i j}} \overline{S_{i j}}\right)^{1 / 2}
\end{aligned}
$$

$$
\begin{aligned}
\overline{S_{i j}} & =\frac{1}{2}\left(\frac{\partial \overline{u_{i}}}{\partial x_{j}}+\frac{\partial \overline{u_{j}}}{\partial x_{i}}\right) \\
\Delta & =\left(\Delta x_{1} \Delta x_{2} \Delta x_{3}\right)^{1 / 3} \\
P & =\bar{p}+\frac{2}{3} q
\end{aligned}
$$

In the equations, the upper line represents the space filter variable; $v_{t}$ is spectral space eddy viscosity coefficient; $v$ is motion viscosity coefficient, taking $1.0 * 10^{-6}$ $\mathrm{m}^{2} \mathrm{sec}^{-1} ; C_{s}$ is Smagorinsky coefficient, taking $0.1 ; \Delta x_{i}$ is grid width; $p$ is pressure; $q$ is spectral space eddy kinetic energy.

4.1.2. Unbalanced Sediment Transport Equation. The unbalanced sediment transport equation can be deduced based on the diffusion theory and displayed as

$$
\frac{\partial S}{\partial t}+\frac{\partial}{\partial x_{i}}\left[\left(u_{i}-\omega_{s} \delta_{i 3}\right) S\right]=\frac{\partial}{\partial x_{i}}\left(\varepsilon_{s} \frac{\partial S}{\partial x_{i}}\right)
$$

where $S$ is sediment concentration; $\delta_{i 3}$ is the Kronecker factor,

$$
\delta_{i 3}= \begin{cases}1, & i=3 \\ 0, & i \neq 3\end{cases}
$$

$\omega_{s}$ is deposition velocity of sediment; $\sigma_{s}$ is the Schmidt factor, generally $0.5 \leq \sigma_{s} \leq 1.0$. However, it [28] suggested $\sigma_{s}=1.0$ in their $3 \mathrm{D}$ numerical model.

\subsubsection{Suspended Sediment Transportation Equation}

$$
\omega_{s} S+\varepsilon_{s} \frac{\partial S}{\partial z}=D_{b}-E_{b}=\gamma_{s}^{\prime} \frac{\partial Z_{b}}{\partial t}
$$

\subsubsection{Bed Load Transport Equation}

(1) Bed Load Discharge. The simulation of bed load discharge is one of the pivotal hypotheses of the $3 \mathrm{D}$ numerical model. The bulk bed load discharge $q_{b^{*}}$ is a function of the particle velocity $U_{b}$, the granule jumps height $\delta_{b}$, and the bulk sediment concentration $S_{b v}$; the relationship shown as (14) and [30] (as (15)) has been one the most popularly used equations:

$$
\begin{aligned}
& q_{b *}=U_{b} \delta_{b} S_{b v} \\
& q_{b *}=\left\{\begin{array}{l}
0.053 \sqrt{\frac{\rho_{s}-\rho}{\rho} g D_{50}^{1.5} \frac{T^{2.1}}{D_{*}^{0.3}}} \quad T<3 \\
0.100 \sqrt{\frac{\rho_{s}-\rho}{\rho} g D_{50}^{1.5} \frac{T^{1.5}}{D_{*}^{0.3}}} \quad T \geq 3
\end{array}\right.
\end{aligned}
$$


where $D_{*}=D_{50}\left(\left(\left(\rho_{s}-\rho\right) / \rho\right) g / v^{2}\right)^{1 / 3}$ is particle parameter and $D_{50}$ is the corresponding particle size with a cumulative percentage distribution of $50 \% ; T=\left(\tau_{b}^{\prime}-\tau_{b, c r}\right) / \tau_{b, c r}$ is the variable of phase shifting, $\tau_{b}^{\prime}$ is the effective shear stress of river bed, $\tau_{b, c r}$ is the critical effective shear stress of river bed, and $\tau_{b}^{\prime}=a_{b} \tau_{b, c r}, \alpha_{b}=\left(C / C^{\prime}\right)^{2}, C$ is the Chezy coefficient [31], $C^{\prime}=18 \log \left(12 R_{b} / 3 D_{90}\right) ; R_{b}$ is the hydraulic radius and $D_{90}$ is the corresponding particle size with a cumulative percentage distribution of $90 \%$;

Afterwards, after measured four sectional bed load discharge and suspended sediment discharge of the Nile, along with a series filed testing date, Abdel-Fattah [32] proposed a new factor $\lambda$ to modify the bed load discharge. Hence, (14) could be rewritten as

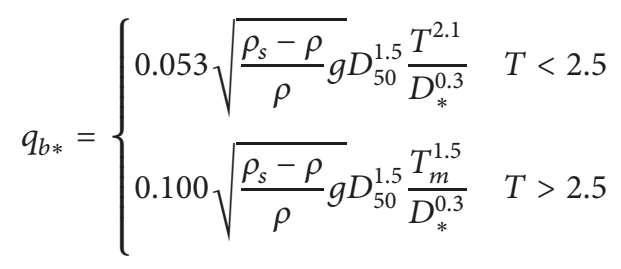

where $T_{m}=\left(\lambda \tau_{b}^{\prime}-\tau_{b, c r}\right) / \tau_{b, c r}, \lambda$ could be calculated by

$$
\begin{gathered}
\lambda=e^{0.45 a+0.2 \beta} \\
\text { or } \lambda=e^{1.8-2.4 \sigma_{g}+0.6 \sigma_{g}^{2}}
\end{gathered}
$$

where $\alpha=1-\sigma_{g}, \beta=d_{50} / d_{90}-d_{10} / d_{50}$, and $\sigma_{g}=\left(d_{84} / d_{50}+\right.$ $\left.d_{50} / d_{16}\right) / 2$.

The critical effective shear stress of river bed $\tau_{b, c r}$ can be deduced by the flat river bed experiment [33], shown as

$$
\tau_{b, c r}=\left(\rho_{s}-\rho\right) g \theta_{c r} D_{50}
$$

Rijin [34] had modified the following by a series research, considering the longitudinal slope of river bed effects on the Shield critical shear stress:

$$
\tau_{b, c r, s}=k_{\beta} k_{\gamma} \tau_{b, c r}
$$

where $k_{\beta}$ is longitudinal slope factor, $k_{\beta}=\sin (\varphi-$ $\beta) / \sin \varphi, \beta$ is the longitudinal slope toe, it is positive when downward grade while it is negative when upward grade, and $\varphi$ is slope of repose. $k_{\gamma}$ is horizontal slope factor, $k_{\gamma}=\cos \gamma\left(1-\tan ^{2} \gamma / \tan ^{2} \varphi\right)$, and $\gamma$ is the horizontal slope toe.

Furthermore, bed load discharge should be revised as the influence of the slope. It could be divided into longitudinal bed load sediment rate and transversal bed load sediment rate.
Formula of modified longitudinal bed load sediment rate after being revised is

$$
q_{b, s *}^{\prime}=\alpha_{s} q_{b, s *}
$$

Transversal bed load sediment rate formula after being revised is

$$
q_{b, n *}^{\prime}=\left[\frac{v_{b}}{u_{b}}+\varepsilon\left(\frac{\tau_{b, c r}}{\tau_{b, s}}\right)^{0.5} \tan \gamma\right] q_{b, s *}^{\prime}
$$

where $q_{b, s *}=\left(u_{b} / U_{b}\right) q_{b *}$ is transversal bed load sediment rate formula; $q_{b, n *}=\left(v_{b} / U_{b}\right) q_{b *}$ is transversal bed load sediment rate formula; $U_{b}$ was confluence velocity of transverse velocity $\left(v_{b}\right)$ and longitudinal velocity $\left(u_{b}\right) ; \alpha_{s}$ is the slope surface influence coefficient; $\tau_{b, s}$ is the longitudinal component of the shear stress for the bed surface; $\varepsilon$ is a parameter (generally equal to 1.5 ).

(2) Unbalanced Sediment Transport Equation of Bed Load. The unbalanced sediment transport equation of bed load was proposed by Rijn [29]:

$$
\frac{\gamma_{s}^{\prime}}{\rho_{s}} \frac{\partial z_{b, b}}{\partial t}+\frac{\partial\left(\delta_{b} S_{b v}^{\prime}\right)}{\partial t}+D_{b}-E_{b}+\frac{\partial q_{b, s}}{\partial x}+\frac{\partial q_{b, n}}{\partial y}=0
$$

where $S_{b v}^{\prime}$ is the bulk sediment concentration of the bottom sand bed; $\partial Z_{b, b} / \partial t$ is the bed deformation caused by the bed load transportation.

Wellington [35] had supposed that

$$
\frac{\gamma_{s}^{\prime}}{\rho_{s}} \frac{\partial z_{b, b}}{\partial t}=\frac{1}{L_{s}}\left(q_{b}-q_{b *}\right)
$$

where $L_{s}$ is the recovery distance of the bottom sand bed, $L_{s}=$ $3 d_{50} D_{*}^{0.5} T^{0.9}$.

When the effects of suspended sediment are very small and can be ignored, (22) can be rewritten as

$$
\frac{1}{L_{s}}\left(q_{b}-q_{b *}\right)+\frac{\partial\left(\delta_{b} S_{b v}^{\prime}\right)}{\partial t}+\frac{\partial q_{b, s}}{\partial x}+\frac{\partial q_{b, n}}{\partial y}=0
$$

Because $q_{b}=U_{b} \delta_{b} S_{b v}^{\prime}$, (24) can be written as

$$
\frac{1}{L_{s}}\left(q_{b}-q_{b *}\right)+\frac{\partial\left(q_{b} / U_{b}\right)}{\partial t}+\frac{\partial q_{b, s}}{\partial x}+\frac{\partial q_{b, n}}{\partial y}=0
$$

Thereby, if the time derivative terms of suspended sediment are ignored, the deformation equation of bed load is

$$
\frac{1}{L_{s}}\left(q_{b}-q_{b *}\right)+\frac{\partial q_{b, s}}{\partial x}+\frac{\partial q_{b, n}}{\partial y}=0
$$


Deformation of river bed is the sum of deformations caused by suspended sediment and bed load sediment.

4.2. Initial Conditions. Physical variables such as current velocity, water level, and turbulent kinetic energy are aggravated $3 \%$ as pulsating part from the original measured date, respectively. Initial value of velocity and water level of every mesh had be calculated by $2 \mathrm{D}$ model and average allocated to every mesh in 3D model. k coefficient and $\varepsilon$ coefficient value could be given by experience. Dynamic water pressure is zero.

\subsection{Boundary Conditions}

4.3.1. Entrance Boundary. Suspended sediment concentration distribution in river entrance section used measured date, or vertical sediment concentration distribution formula. Bed load sediment concentration in entrance section is given to keep no deformation occurring in the section.

4.3.2. Export Boundary. The normal gradient of suspended sediment concentration in export section is zero.

\subsubsection{Wall Surface and Bottom Surface Boundaries}

(1) Current Velocity at the Surfaces. The walls and bottom of the river are coarse surfaces; they would hinder the water flow away. In this 3D model, the "law of the wall" (Ban, 1995) is used to simulate the current velocity at the interfaces, which is the water and solid interface.

$$
\frac{u}{u^{*}}=\frac{1}{k} \ln \left(\frac{z u^{*}}{v}\right)+B
$$

where $u^{*}$ is friction velocity; $k=0.41 ; B=5.0$.

At the meanwhile, the shear stress at the water up surface is supposed to be zero, and the shear stress at the water and soil interface can be deduced from

$$
\frac{\tau_{w}}{\rho}=\nu \frac{\partial u}{\partial z}
$$

(2) Stress at the Water-Soil Interface. The stress at the watersoil interface can be calculated by

$$
\begin{aligned}
& \tau_{b x}=\rho C_{d} u_{b} \sqrt{u_{b}^{2}+v_{b}^{2}} \\
& \tau_{b y}=\rho C_{d} v_{b} \sqrt{u_{b}^{2}+v_{b}^{2}}
\end{aligned}
$$

In the moving bed model, current velocity can be calculated by (29) use logarithmic wall function:

$$
\frac{u_{b}}{u_{*}}=\frac{1}{k} \ln \frac{z}{z_{0}}
$$

where friction velocity $u_{*}=\sqrt{\tau_{b} / \rho}$. Thus, $C_{d}$ can be calculated by $(31) \sim(34)$ :

$$
\begin{aligned}
C_{d} & =\frac{1}{\left((1 / k) \ln \left(z_{b} / z_{0}\right)\right)^{2}} \\
z_{0} & =\frac{v}{E u_{*}} \\
E & =e^{[\kappa(B-\Delta B)]}
\end{aligned}
$$

$$
\begin{aligned}
& \Delta B= \begin{cases}0 & R_{e}<2.25 \\
{\left[B-8.5+\frac{1}{\kappa} \ln R_{e}\right] \sin \left[0.428+\ln R_{e}-0.811\right]} & 2.25 \leq R_{e}<90 \\
B-8.5+\frac{1}{\kappa} \ln R_{e} & R_{e} \geq 90\end{cases} \\
& R_{e}=\frac{u_{*} k_{s}}{v}
\end{aligned}
$$

where $z_{0}$ is the height when current velocity is equal to 0 ; $\mathrm{E}$ is rough parameters of bed surface; $\mathrm{B}=5.2 ; k_{s}$ is rough height of river bottom or riverbank, $k_{s}=2.5 d$ [30].

(3) Sediment Concentration at the Surfaces. These is no sediment exchange at the surfaces, and sediment concentration at the surfaces can be deduced from

$$
\omega_{s} S+\left.\varepsilon_{s} \frac{\partial S}{\partial z}\right|_{z=z_{\text {free }}}=0
$$




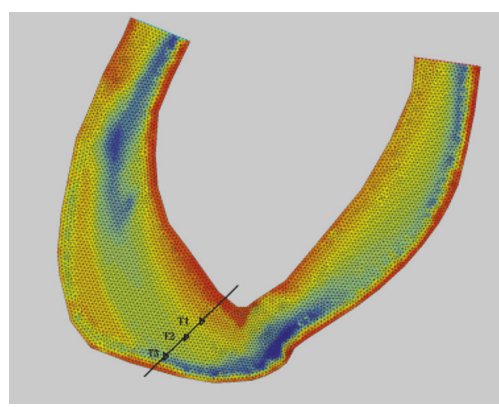

(a)

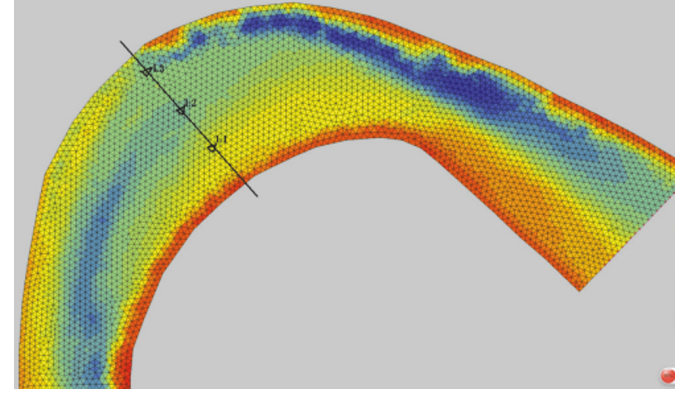

(b)

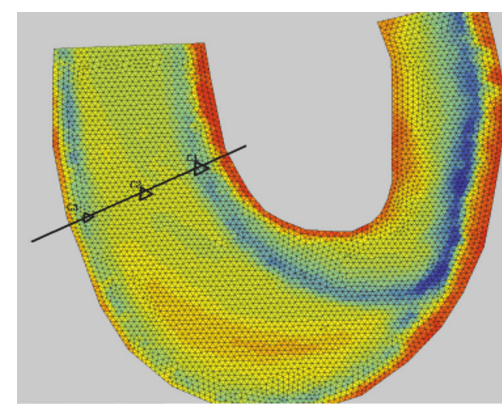

(c)

Figure 12: Mesh details of: (a) Tiaoguan CR, (b) Laijiapu CR, and (c) Qigongling CR.

(4) Sediment Concentration at the Near-Bed Region. The nearbed region is the layer in the water but right near the river bed, the sediment concentration of the near-bed region $S_{b}$ is a significant hypothesis for the $3 \mathrm{D}$ model, and it can be calculated by

$$
S=S_{b}-S_{b *}+c e^{-\left(\omega / \varepsilon_{s}\right) z}
$$

And replacing the variables with the known equations: $z=$ $\delta_{b}, S=S_{b}, z=z_{k}-\delta_{b}$, and $S=S_{k}$, (40) can be rewritten as follows:

$$
S_{b}=S_{k}+S_{b *}\left(1-e^{-\left(\omega / \varepsilon_{s}\right)\left(z_{k}-\delta_{b}\right)}\right)
$$

(5) Sediment Carrying Capacity of the Near-Bed Region. As a more commonly used method at present, van Rijn is used to calculate sediment carrying capacity. Sediment carrying capacity of the near-bed region can be deduced from

$$
\begin{aligned}
S_{v b}^{*} & =0.015 \frac{d_{50} T^{1.5}}{a D_{*}^{0.3}} \\
D_{*} & =d_{50}\left(\frac{\left(\left(\rho_{s}-\rho\right) / \rho\right) g}{v^{2}}\right)^{1 / 3} \\
a & =0.5 k_{s} \\
a & \geq 0.01 d_{50}
\end{aligned}
$$

4.4. Computational Meshes. Unstructured grid mesh method is used in the proposed 3D model, and three typical meandering reaches have been chosen to verify the mesh technique:

(1) Tiaoguan CR. Tiaoguan CR is about $11 \mathrm{~km}$ in length and $1.1 \sim 2 \mathrm{~km}$ in width, the mesh size is $20 \sim 30 \mathrm{~m}$ in the horizontal direction, and along the water channel depth direction there are 10 layers grids, and there are a total of 5925 grids, shown as Figure 12(a).
(2) Laijiapu CR. Laijiapu CR is about $8 \mathrm{~km}$ in length and $0.7 \sim 1.3 \mathrm{~km}$ in width, the mesh size is $17 \sim 30 \mathrm{~m}$ in the horizontal direction, and along the water channel depth direction there are 10 layers grids, and there are a total of 3604 grids, shown as Figure 12(b).

(3) Chibakou CR. Chibakou CR is about $9 \mathrm{~km}$ in length and $0.7 \sim 1.7 \mathrm{~km}$ in width, the mesh size is $20 \sim 50 \mathrm{~m}$ in the horizontal direction, and along the water channel depth direction there are 10 layers grids, and there are a total of 4905 grids, shown as Figure 12(c).

\subsection{Verification}

4.5.1. Verification by Flume Test. Onishi classic model test [36] was used to validate the mathematical model. The given water level at the model entrance was $0.1333 \mathrm{~m}$, the average current velocity was $0.536 \mathrm{~m} / \mathrm{s}$, and the average diameter of the particles was $0.25 \mathrm{~mm}$, shown as Figure 13. Verification results show that the average water lever errors between calculated value and testing value by total sediment transport model (TSTM) are less than $0.06 \mathrm{~m}$ in all sections, while errors are less than $0.04 \mathrm{~m}$ by suspended sediment transport model (SSTM). Thus, TSTM is chosen to simulate the river, shown as Figure 14. Vertical flow velocity errors are mainly produced by fluctuation of water level. The errors are less than $0.2 \mathrm{~m} / \mathrm{s}$, shown as Figure 15 . The predicted sediment concentration in the top layer was almost the same as the testing data, while the predicted sediment concentration of in bottom layer was vibrating within $100 \mathrm{~g} / \mathrm{m}^{3}$ at the testing data, shown as Figure 16.

Briefly, the parameters calibration results indicate that the proposed 3D model displayed a reasonable agreement with the testing data, and could be used to do comprehensive verification for fixed bed model and moving bed model.

4.5.2. Verification by Measured Data. The fixed bed model is vivificated by measured data of February 2010. Figures 17 and 18 show the velocity comparison of cross section and longitudinal section in chosen reaches. Velocity errors of 


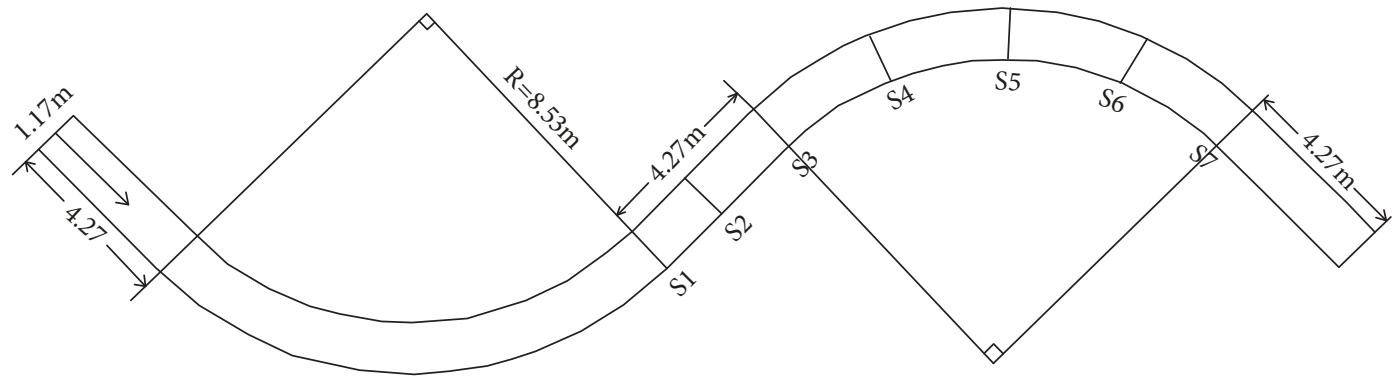

FIgURE 13: Onishi classic model test plane layout.
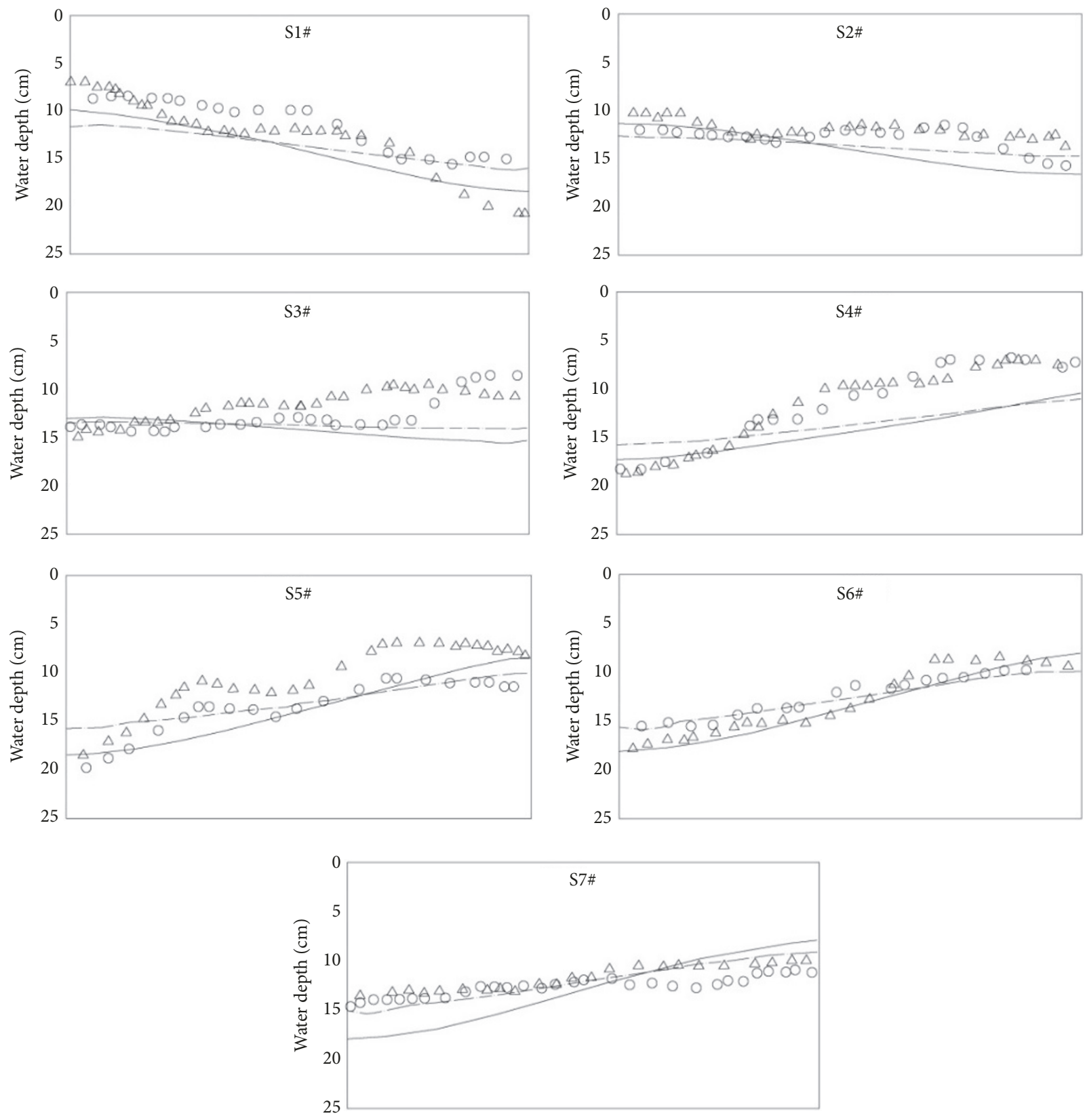

FIGURE 14: Water depth value contrast. O: the first test set; $\triangle$ : the second test set; —: calculated value by TSTM. - -: calculated value by SSTM. 

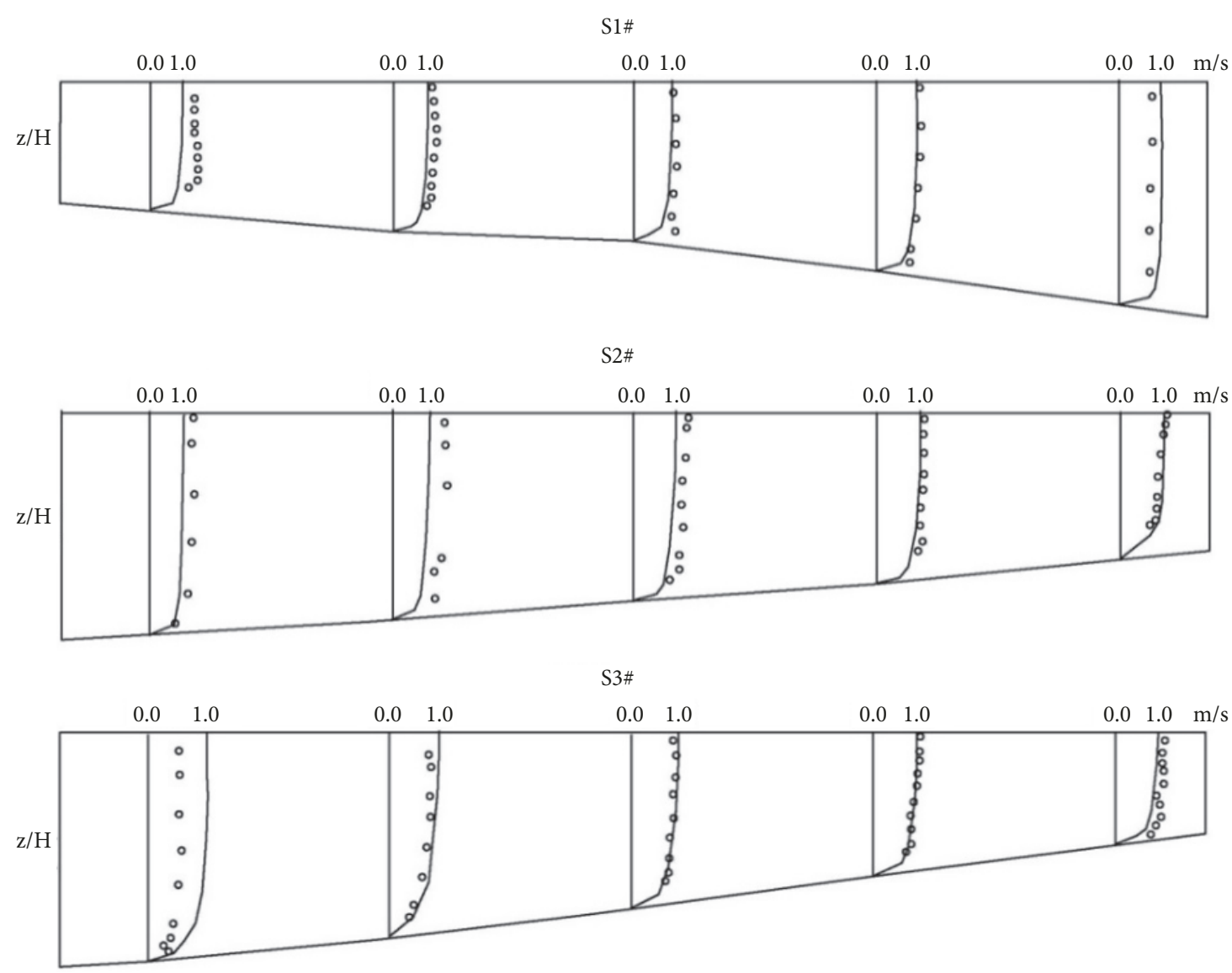

FIGURE 15: Vertical flow velocity contrast. —: calculated value. O: test value.

cross section are within $0.2 \mathrm{~m} / \mathrm{s}$. Velocity errors of longitudinal section are within $0.4 \mathrm{~m} / \mathrm{s}$.

The moving bed model used the geomorphic data of February 2012 as the original inputs and used the geomorphic data of October 2012 as the verification materials. Figure 19 shows that the predicted scouring or depositing tendency of the reaches is the same as the measured data and the predicted variation of the sediment is slightly vibrating within $20 \%$ error near the measured data, which already meet the calculation accuracy of engineering projects.

According to the verification of moving bed model, the proposed $3 \mathrm{D}$ model behaves reliably in predict the transportation properties of water, sediment, and even the deformation of the river bed. It can be used in further study on river evolution mechanism and can be used in broader prediction of river evolution disciplines.

\section{Conclusions}

(1) Jingjiang reach is a typical meandering reach containing many local cured reaches downstream the TGP. Impounding of TGR has changed the incoming water and sediment condition in downstream river, leading to an obvious change of evolution disciplines. According to the measured data, curved reaches in Jingjiang could be divided into Type A and Type B. Type A is widely distributed. Its concave bank is scoured while convex bank is deposited before impounding of TGR, but concave bank is deposited and convex bank is scoured after impounding of TGP. Type B is mainly distributed in sharp curved reaches. Its convex bank scouring and even cutting-bend before impounding of TGR, however the evolution tendency had aggravated after impounding of TGR.

(2) Evolution mechanism of curved reaches is affected by flow and sediment transport in longitudinal, transverse and vertical directions. Moreover, Jingjiang reach bed consists of fine sand. It makes transport mechanism of suspended sediment and bed load more complicated. Thus, new 2D model and 3D mathematical models which adapting to the Jingjiang curved reachs were proposed to simulate evolution disciplines of curved reaches.

(3) Measured data and Onishi test results were used to verify numerical models. The $2 \mathrm{D}$ model verification showed that water level errors between calculated values and measure values were within $0.11 \mathrm{~m}$; branch diversion ratio errors were within $2 \%$; flow velocity errors were within $0.2 \mathrm{~m} / \mathrm{s}$. 

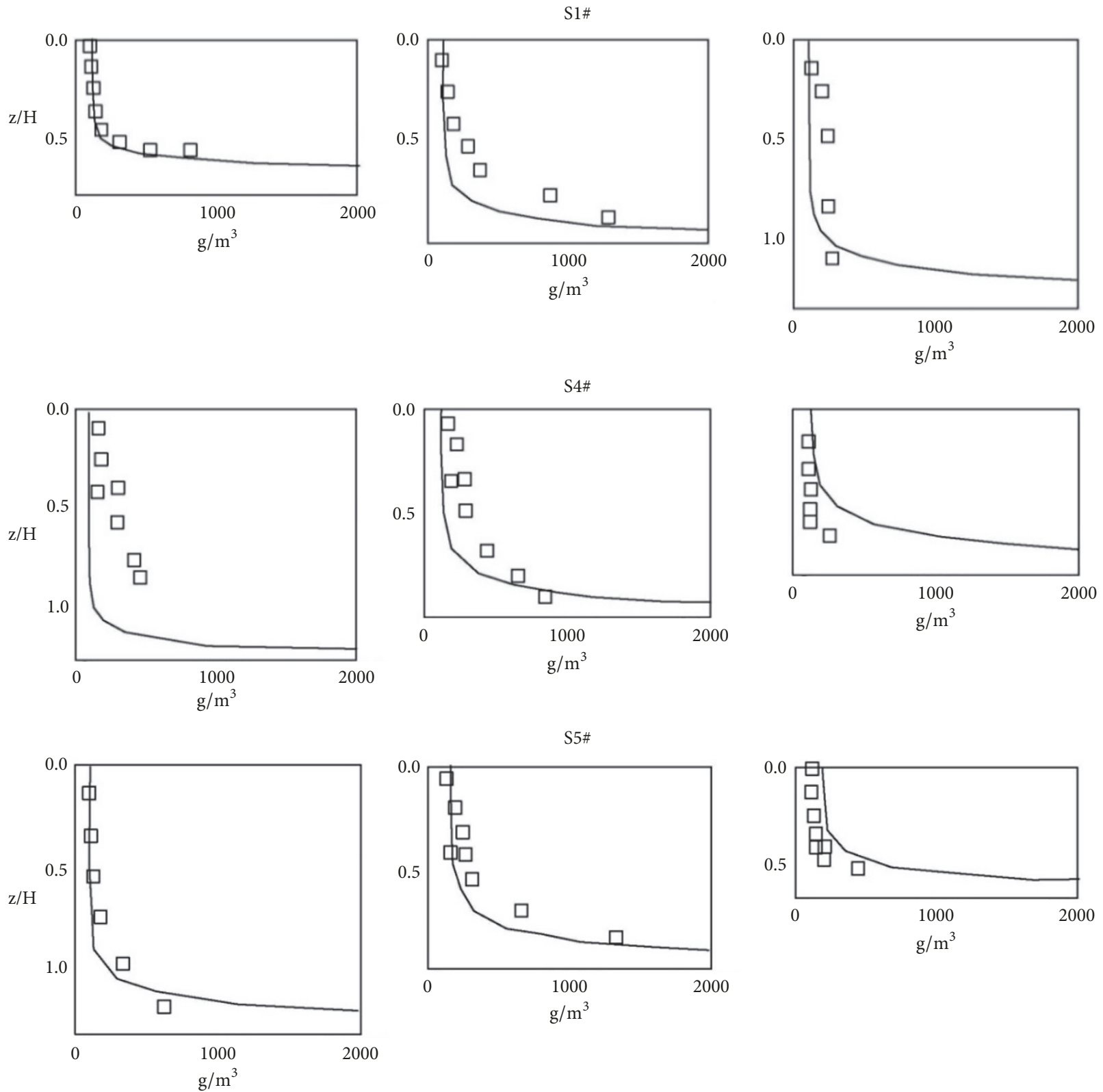

Figure 16: Sediment concentration value contrast. —: calculated value. $\square$ : test value.

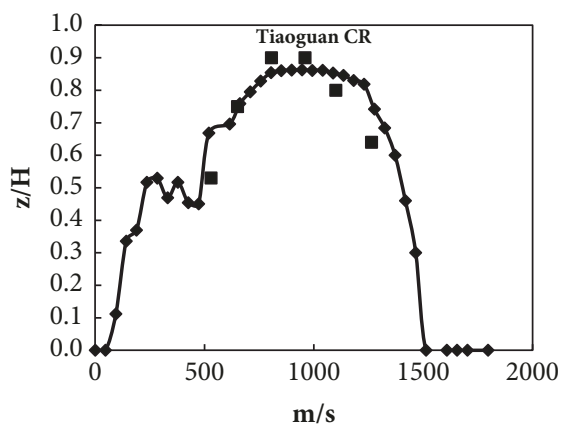

Calculated value

Measured value

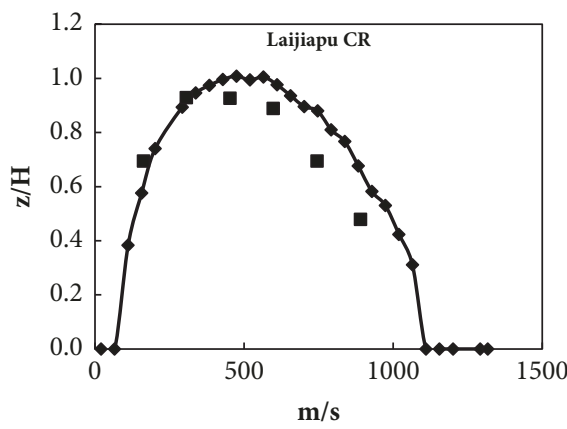

Calculated value

- Measured value

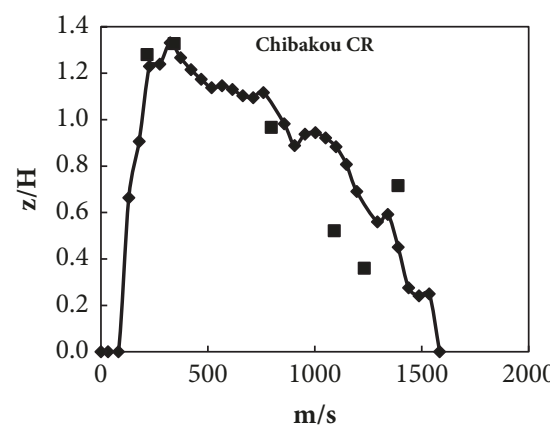

Calculated value

Measured value

FIGURE 17: Velocity contrast of cross section. 


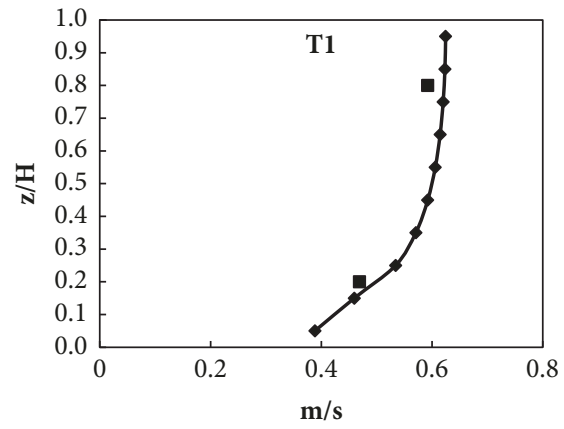

$\rightarrow$ Calculated value

- Measured value

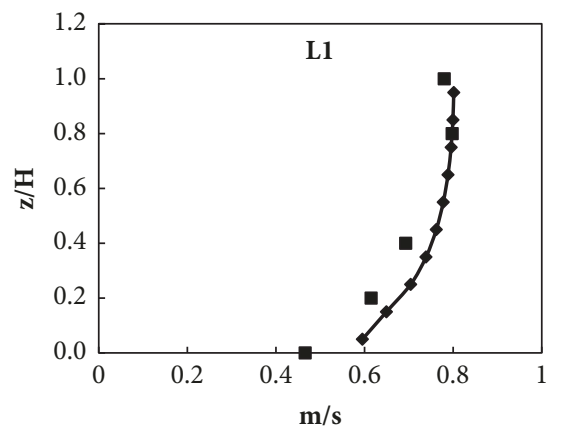

$\rightarrow$ Calculated value

- Measured value

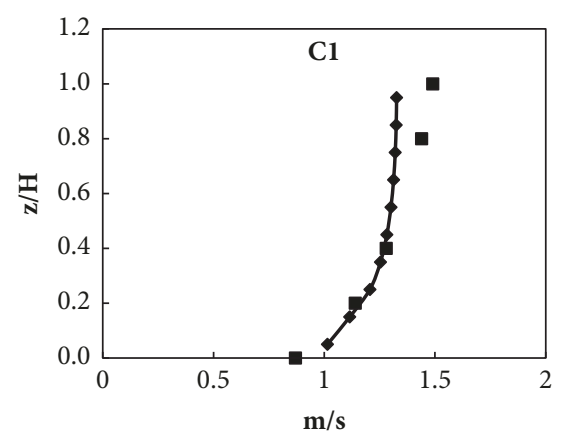

- Calculated value

- Measured value

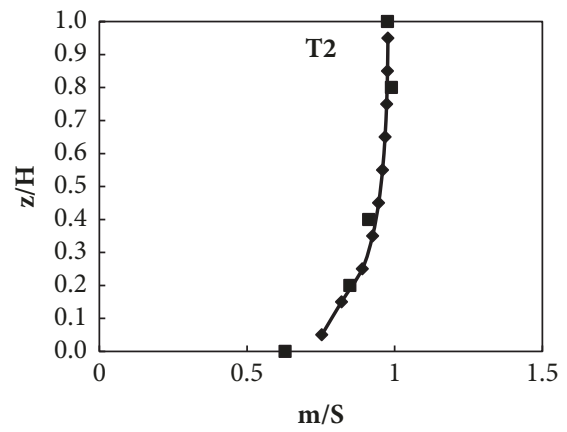

Calculated value

Measured value

(a)

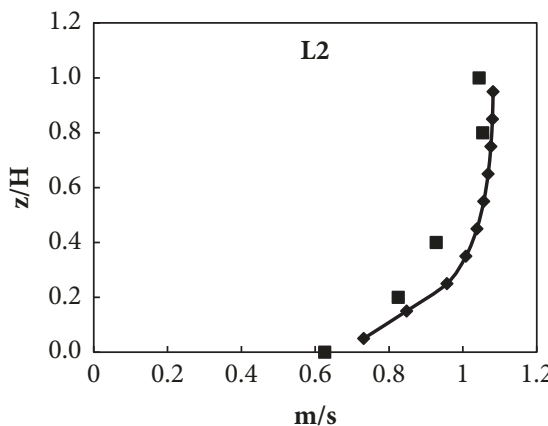

Calculated value

Measured value

(b)

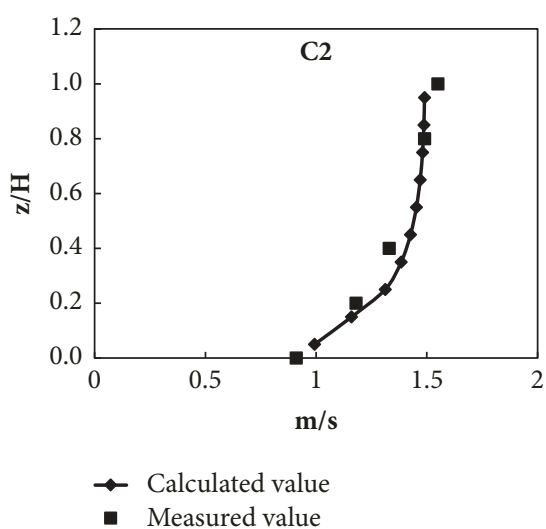

(c)

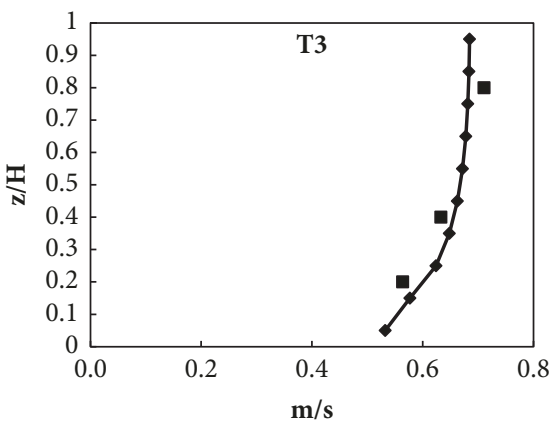

$\rightarrow$ Calculated value

- Measured value

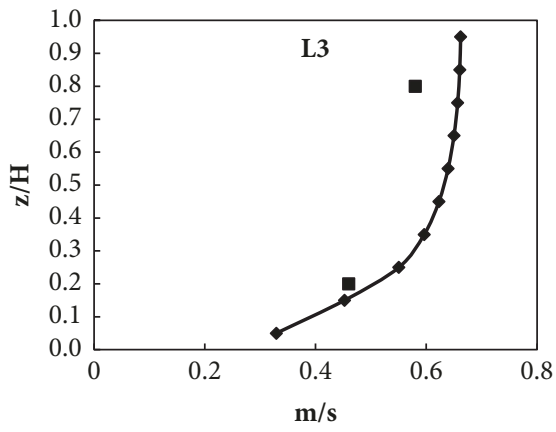

Calculated value

- Measured value

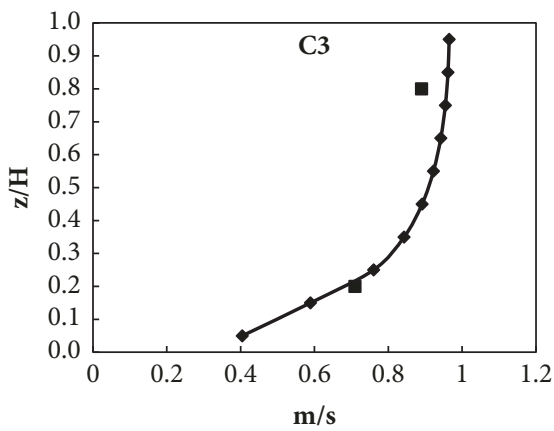

- Calculated value

Measured value

FIGURE 18: Velocity contrast of longitudinal section: (a) Tiaoguan CR, (b) Laijiapu CR, and (c) Qigongling CR.

(4) The 3D model verification showed that water lever errors were within $0.04 \mathrm{~m}$; vertical flow velocity errors were within $0.2 \mathrm{~m} / \mathrm{s}$; sediment concentration was within $100 \mathrm{~g} / \mathrm{m}^{3}$; variable quantity of sediment errors was within $15.2 \%$. Comparing calculated value with measure data, velocity errors of cross section were within $0.2 \mathrm{~m} / \mathrm{s}$; velocity errors of longitudinal section were within $0.4 \mathrm{~m} / \mathrm{s}$; sediment variation errors were within $20 \%$. The results indicated that the proposed 3D model displayed a reasonable agreement with the testing and measure data and could be used to research the evolution mechanism of curved reaches.

\section{Data Availability}

No data were used to support this study. 


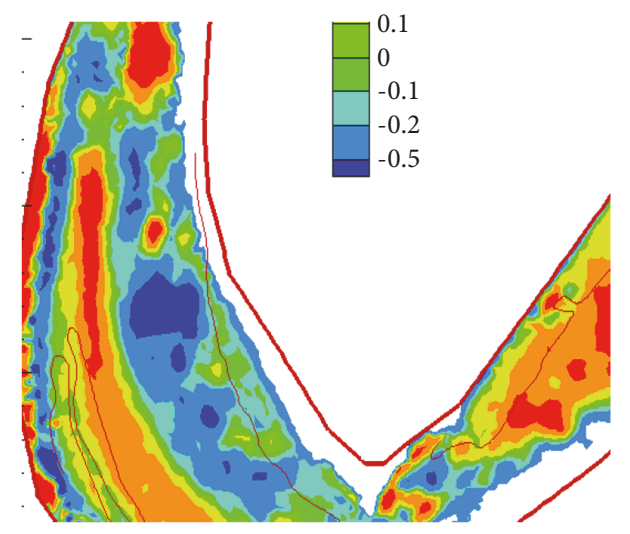

(a)

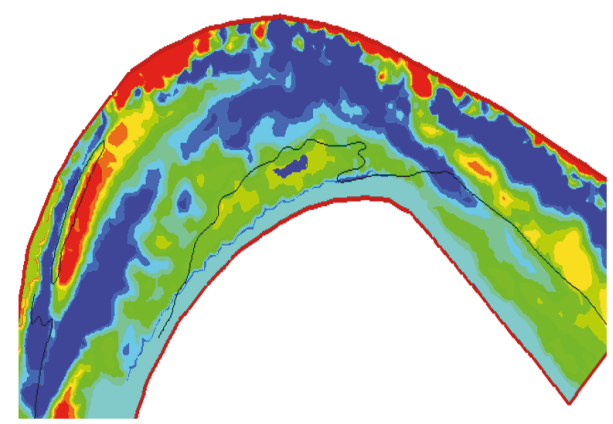

(c)

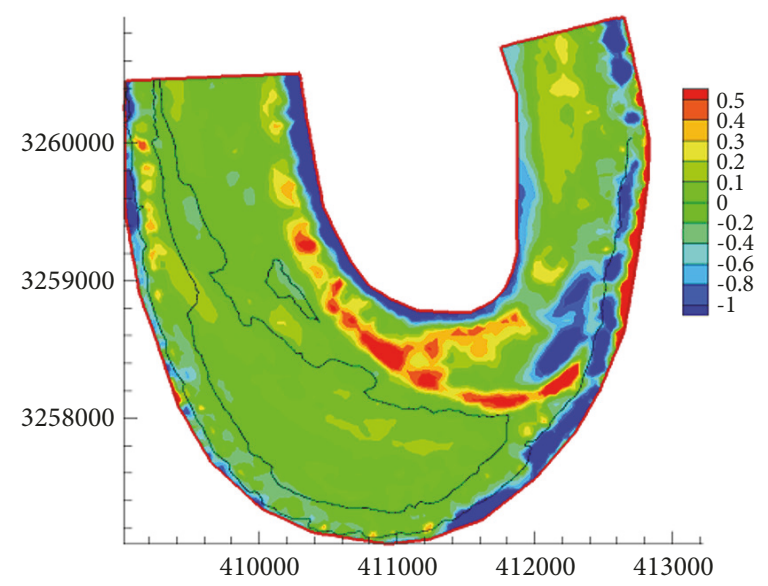

(e)

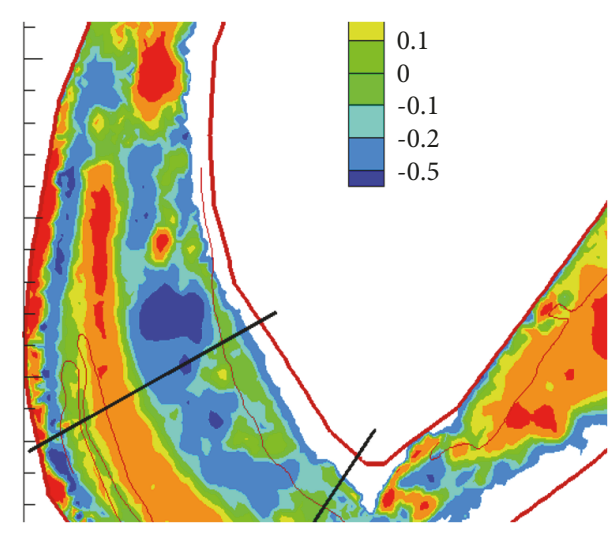

(b)

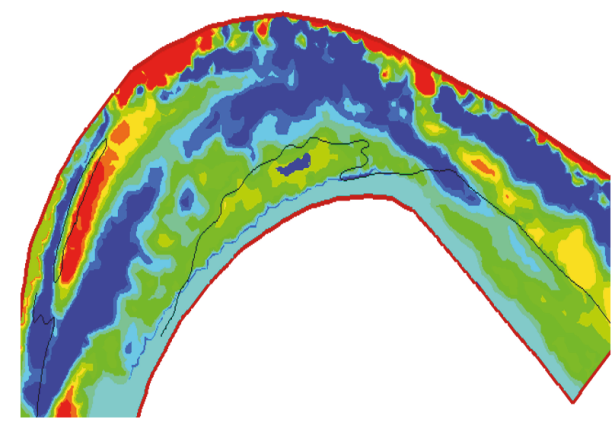

(d)

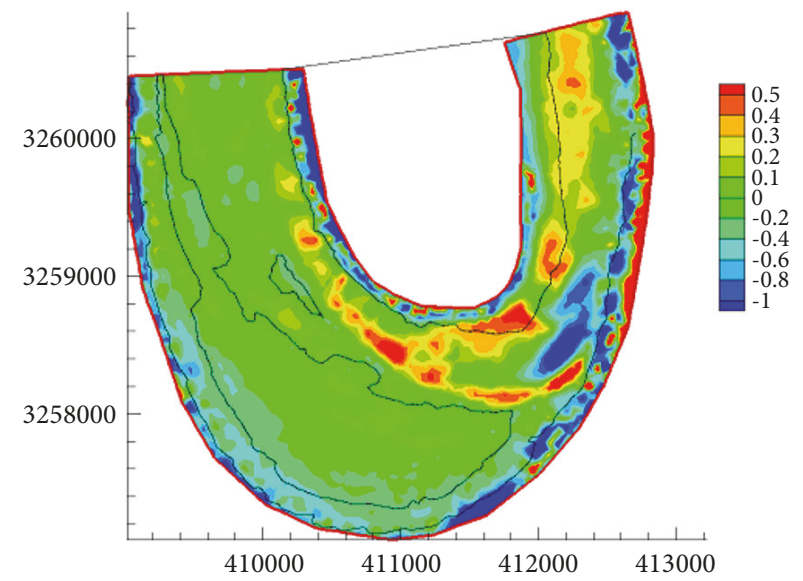

(f)

FIGURE 19: Scouring or depositing distribution diagram from February, 2012 to October, 2012. (a) Tiaoguan CR, calculated value. (b) Tiaoguan CR, measured data. (c) Laijiapu CR, calculated value. (d) Laijiapu CR, measured data. (e) Qigongling CR, calculated value. (f) Qigongling $\mathrm{CR}$, measured data.

\section{Conflicts of Interest}

The authors declare that there are no conflicts of interest regarding the publication of this paper.

\section{Acknowledgments}

This research was financial supported by the National Key Research and Development Program of China (nos. 2016YFC0402105 and 2016YFC0402307). This article would be a significant component of this program, but the copyright and the related interest of this article belong to the authors.

\section{References}

[1] Y. P. Yang, M. J.Zhang, and Z. H. Sun, “The relationship between water level change and river channel geometry adjustment in the downstream of the Three Gorges Dam," Journal of Geographical Sciences, vol. 28, no. 2, pp. 193-211, 2018.

[2] Z. Chen, Z. Wang, B. Finlayson, J. Chen, and D. Yin, "Implications of flow control by the Three Gorges Dam on sediment and 
channel dynamics of the middle Yangtze (Changjiang) River, China," Geology, vol. 38, no. 11, pp. 1043-1046, 2010.

[3] L. B. Leopold and W. B. Langbein, "Variability of river patterns," River Scientific American, vol. 71, no. 6, pp. 769-793, 1960.

[4] F. Engelund, "Flow and bed topography in channel bends," Journal of the Hydraulics Division, vol. 100, no. 3, pp. 1631-1648, 1974.

[5] K. Blanckaert, M. G. Kleinhans, S. J. Mclelland et al., "Flow separation at the inner (convex) and outer (concave) banks of constant-width and widening open-channel bends," Earth Surface Processes and Landforms, vol. 38, no. 7, pp. 696-716, 2013.

[6] N. R. B. Olsen, "Evolution of across meander necks in Powder," Journal of Hydraulic Engineering, vol. 129, no. 5, pp. 366-372, 2003.

[7] V. B. Smith and D. Mohrig, "Geomorphic signature of a dammed Sandy River: The lower Trinity River downstream of Livingston Dam in Texas, USA," Geomorphology, vol. 297, pp. 122-136, 2017.

[8] D. Jia, X. Shao, X. Zhang, Y. Lu, and P. Hei, "Morphological responses in a meandering and island-braided reach of the Middle Yangtze River to the Three Gorges Reservoir impoundment," International Journal of Sediment Research, vol. 31, no. 2, pp. 131138, 2016.

[9] K. Xu, J. D. Milliman, and Z. Yang, "Yangtze sediment decline partly from Three Gorges Dam," EOS Transactions American Geophysical Union, vol. 87, no. 19, pp. 185-190, 2013.

[10] X. X. Luo, S. L. Yang, and J. Zhang, "The impact of the Three Gorges Dam on the downstream distribution and texture of sediments along the middle and lower Yangtze River (Changjiang) and its estuary, and subsequent sediment dispersal in the East China Sea," Geomorphology, vol. 179, pp. 126-140, 2012.

[11] W. C. Yu, "Preliminary study on forming condition of lower Jingjiang meandering channels of middle Yangtze River," Journal of Yangtze River Scientific Research Institute, vol. 23, no. 6, pp. 9-13, 2006.

[12] L. Jiang, Y. Li, Z. Sun, and C. Huang, "Channel evolution of Jingjiang reach and its influences on waterway after impoundment of the Three Gorges Project," Yingyong Jichu yu Gongcheng Kexue Xuebao/Journal of Basic Science and Engineering, vol. 18, no. 1, pp. 1-10, 2010.

[13] J. Xia, Q. Zong, S. Deng, Q. Xu, and J. Lu, "Seasonal variations in composite riverbank stability in the Lower Jingjiang Reach, China," Journal of Hydrology, vol. 519, pp. 3664-3673, 2014.

[14] D. Jia, X. Shao, H. Jiang, Y. Shen, X. Zhang, and Y. Shang, "Responses of channel migration to changes of flow and sediment regime in the Jingjiang reach of the middle Yangtze River: II: Differences between upper and lower sections," Shuikexue Jinzhan/Advances in Water Science, vol. 24, no. 2, pp. 205-211, 2013.

[15] S. Deng, J. Xia, M. Zhou, and J. Li, "Conceptual model of bank retreat processes in the Upper Jingjiang Reach," Chinese Science Bulletin, vol. 61, no. 33, pp. 3606-3615, 2016.

[16] J. Y. Lu, G. Qu, and F. Z. Li, "Channel evolution of the reach from Xiongjiazhou to Chenglingji in lower Jingjiang river and regulation considerations," Journal of Yangtze River Scientific Research Insititute, vol. 28, no. 11, pp. 113-118, 2011.

[17] Z. Wang, Z. Chen, M. Li, J. Chen, and Y. Zhao, "Variations in downstream grain-sizes to interpret sediment transport in the middle-lower Yangtze River, China: A pre-study of ThreeGorges Dam," Geomorphology, vol. 113, no. 3-4, pp. 217-229, 2009.
[18] J. Xia, S. Deng, M. Zhou, J. Lu, and Q. Xu, "Geomorphic response of the Jingjiang Reach to the Three Gorges Project operation," Earth Surface Processes and Landforms, vol. 42, no. 6, pp. 866-876, 2017.

[19] M. Zhou, J. Xia, J. Lu, S. Deng, and F. Lin, "Morphological adjustments in a meandering reach of the middle Yangtze River caused by severe human activities," Geomorphology, vol. 285, pp. 325-332, 2017.

[20] Z. T. Xie, X. F. Zhang, and J. Yuan, "Study and application of 2-D horizontal mathematical model for flow and sediment in generalized curvilinear coordinate," Journal of Sedimentary Research, vol. 6, pp. 58-64, 2005.

[21] M. Li, L. Liu, and L. Zheng, "Study of two dimensional flow and sediment numerical model of Ouchikou reach in mid Yangtze river," Yangtze River, vol. 42, no. 15, pp. 63-91, 2011.

[22] J. Wang, C. Zhang, and J. Ni, "Method of generating twodimensional body-fitted," Hefei University of Technology, vol. 29, no. 12, pp. 1549-1551, 2006.

[23] Y. Dong, "Research on generating method of 2-D river-regimefitted orthogonal grid for river channels and its application," Changjiang Kexueyuan Yuanbao/ Journal of Yangtze River Scientific Research Institute, vol. 18, no. 4, pp. 14-17, 2001.

[24] Y. Y. Ban, S. Jin, and W. Y. Ding, "Calculation and application of mathematical model for three-dimensional river flow," Journal of Water Resources and Architectural Engineering, vol. 11, no. 4, pp. 153-156, 2013 (Chinese).

[25] T. Iliescu and P. F. Fischer, "Large eddy simulation of turbulent channel flows by the rational large eddy simulation model," Physics of Fluids, vol. 15, no. 10, pp. 3036-3047, 2003.

[26] J. Smagorinsky, "General circulation experiments with the primitive equations: I. The basic equations," Monthly Weather Review, vol. 91, pp. 99-164, 1963.

[27] J. W. Deardorff, "On the magnitude of the subgrid scale eddy coefficient," Journal of Computational Physics, vol. 7, no. 1, pp. 120-133, 1971.

[28] W. Wu, W. Rodi, and T. Weaka, "3D numerical modeling of flow and sediment transport in open channels," Journal of Hydraulic Engineering, vol. 126, no. 1, pp. 4-15, 2000.

[29] L. C. Van Rijn, "Sediment transport, part I: Bed load transport," Journal of Hydraulic Engineering, vol. 113, no. 9, pp. 1189-1190, 1987.

[30] L. C. van Rijn, "Equivalent roughness of alluvial bed," Journal of Hydraulic Engineering, vol. 109, no. 9, pp. 1250-1251, 1983.

[31] A. M. Latyshenkov, "Comparison of various formulas for determining the Chezy coefficient," Hydrotechnical Construction, vol. 7, no. 7, pp. 663-668, 1973.

[32] S. Abdel-Fattah, A. Amin, and L. C. Van Rijn, "Sand transport in Nile River, Egypt," Journal of Hydraulic Engineering, vol. 130, no. 6, pp. 488-500, 2004.

[33] Z. F. Chui, X. F. Zhang, and X. X. Feng, "Numerical simulation on scour around spur-dike by $3 \mathrm{D}$ turbulent model," Journal of Hydrodynamics, vol. 1, pp. 33-41, 2008.

[34] L. C. V. Rijn, M. W. C. Nieuwjaar, and T. V. D. Kaay, “Transport of fine sands by currents and waves," Journal of Waterway Port Coastal Ocean Enginning, vol. 119, no. 2, pp. 123-143, 1993.

[35] N. B. Wellington, "A sediment-routing model for alluvial streams Sediment Transport," 1978.

[36] Y. Onishi, "Sediment-contaminant transport model," Journal of Hydraulic Engineering, vol. 109, no. 5, pp. 771-773, 1983. 


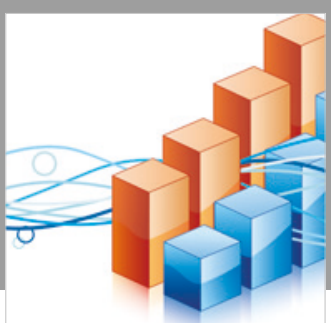

Advances in

Operations Research

\section{-n-m}
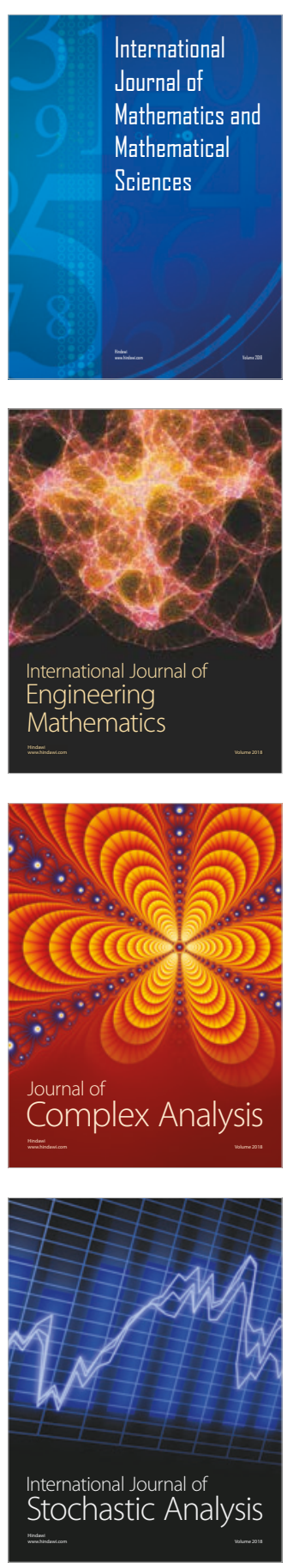
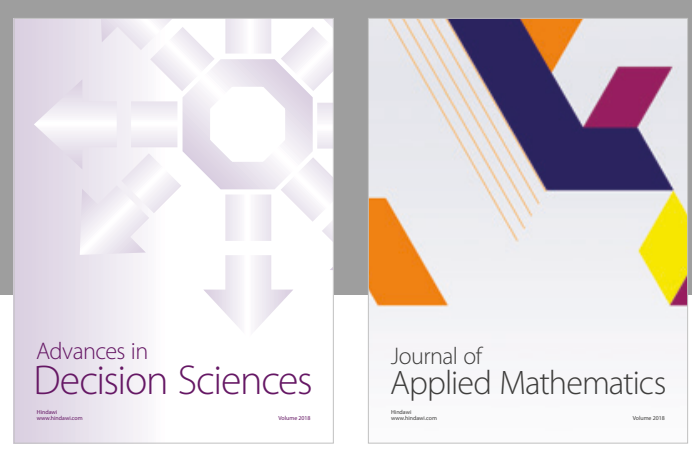

Journal of

Applied Mathematics
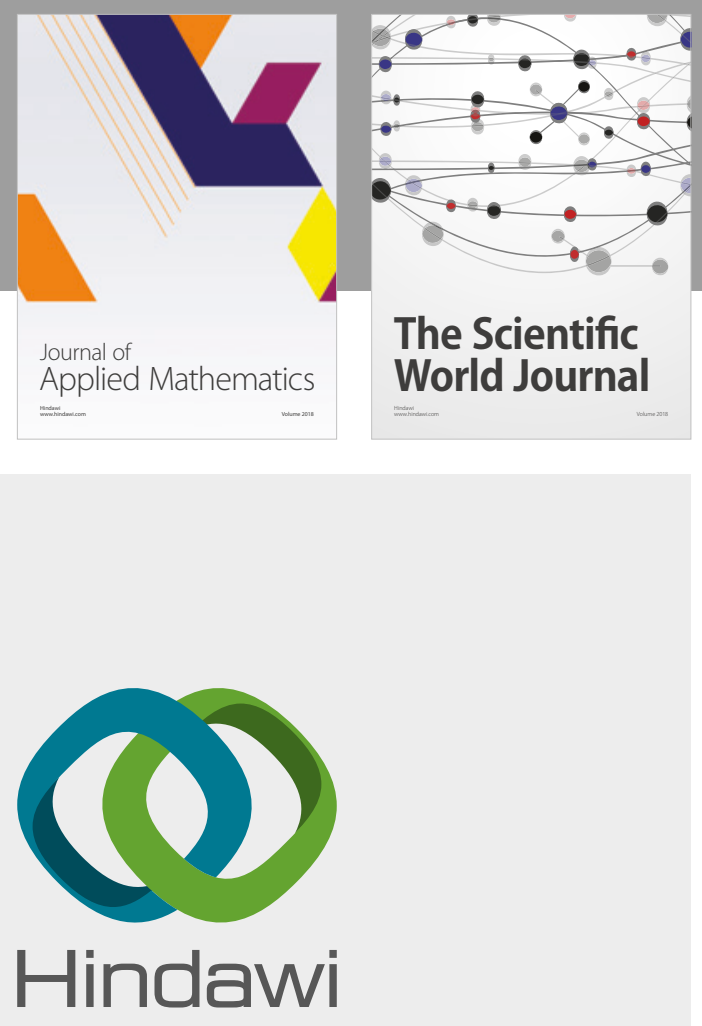

Submit your manuscripts at

www.hindawi.com

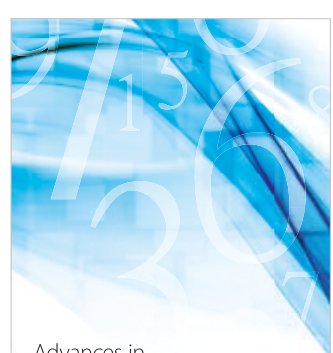

Advances in
Numerical Analysis
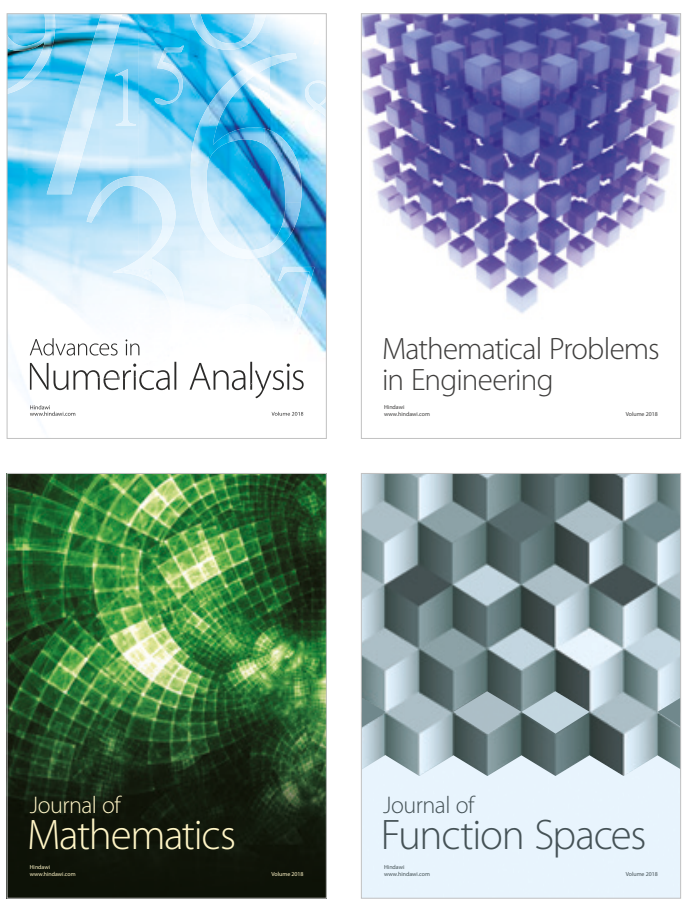

Mathematical Problems in Engineering

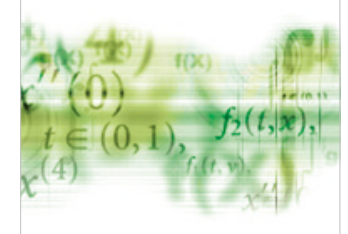

International Journal of

Differential Equations

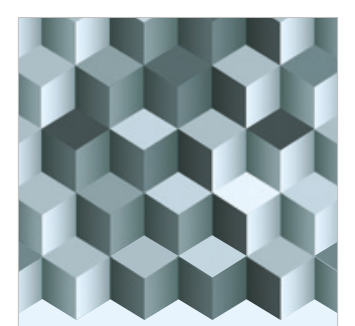

Journal of

Function Spaces

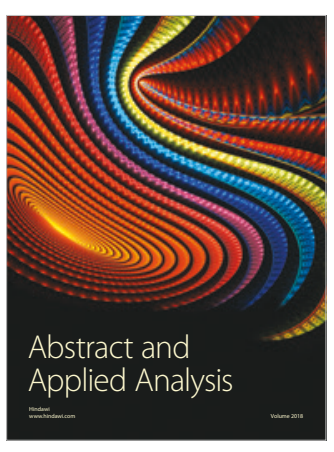

The Scientific

World Journal

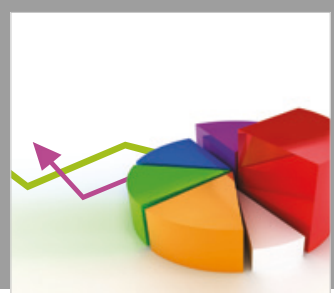

Journal of

Probability and Statistics
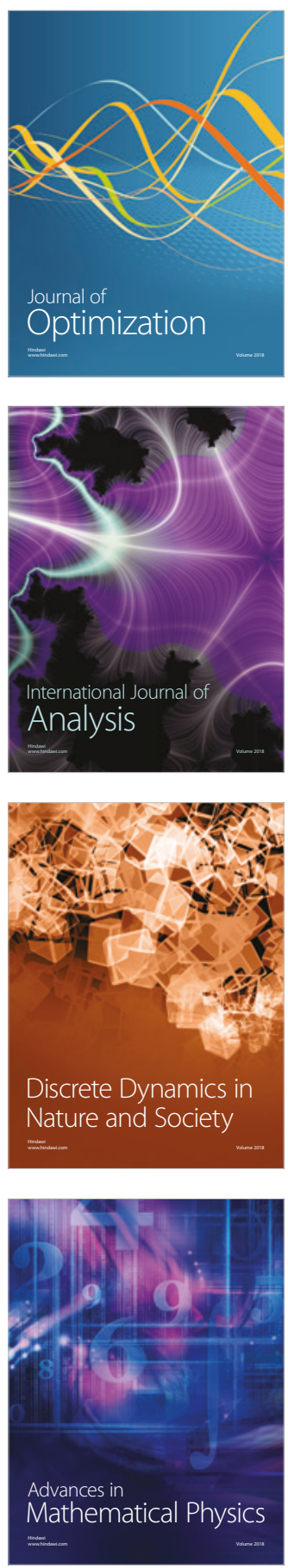